\title{
EL DESARROLLO DE LOS MODELOS URBANÍSTICOS EN IBEROAMÉRICA DESDE UN PRISMA DE SOSTENIBILIDAD
}

\author{
Autor Fernando García Rubio \\ Técnico de administración general del Ayuntamiento de Madrid \\ Profesor titular de derecho administrativo URJC
}

Artículo Recibido: 20/11/2017

Artículo Aceptado: 23/12/2017

\begin{abstract}
RESUMEN
El presente trabajo es una introducción a los efectos de la sostenibilidad en el ordenamiento jurídico urbanístico iberoamericano partiendo del análisis comparado de cuatro países: España como primer país regulador desde el punto de vista jurídico del urbanismo en ese ámbito, ya desde las leyes de Indias y la Ley del suelo de 1956; Colombia como país con un desarrollado pero no "europeo", sistema jurídicourbanístico; República Dominica cuyas previsiones constitucionales aún no fueron plasmadas en una Ley específica en la materia; y, Uruguay con una reciente legislación que se impregna de los principios de la sostenibilidad.
\end{abstract}

\section{PALABRAS CLAVE}

Planificación, urbanismo, sostenibilidad, ordenación del territorio, función social y medio ambiente

\section{Key words}

Planning, urban planning, sustainability, spatial planning, social function and the environment

\section{INTRODUCCIÓN}

La planificación urbana es un elemento común a la mayor parte de los países de nuestro planeta como técnica de ordenación de los desarrollos de las poblaciones, esta técnica que se incorpora lógicamente a los ordenamientos jurídicos, tiene diversas manifestaciones en los correspondientes estados soberanos, pero en el entorno iberoamericano mantiene una conjunción de determinaciones en cuanto a la técnica muy asimilables independientemente de las manifestaciones concretas de cada país.

WPS RI-SHUR, no6, 2017, vol.2, ISSN: 2387-1768

MONOGRÁFICO SOBRE LAS ESTRATEGIAS DE DESARROLLO URBANO

SOSTENIBLE E INTEGRADO (EDUSI) 


\section{WPSReview International on Sustainable \\ Housing and Urban Renewal (RI-SHUR)}

Ahora bien, la planificación se incorpora a un conjunto de determinaciones de derecho de la ordenación territorial y más concretamente con el derecho urbanístico junto a otras modalidades de técnicas como son la ejecución de planeamiento, más o menos regladas, y el control sobre la edificación, uso del suelo y la lucha contra la informalidad en la edificación.

El objeto de esta aproximación es realizar un aspecto comparado entre lo que es el régimen jurídico urbanístico en cuatro países iberoamericanos, a los efectos de tomar un análisis desde el punto de vista del desarrollo de la normativa urbanística y por tanto los modelos de ejecución del planeamiento en un marco de sostenibilidad.

Para ello, y partiendo de una madurez de un sistema que tiene más de 61 años desde la aprobación de la ley sobre el Régimen del Suelo y Ordenación Urbana, de 12 de mayo de 1956, en España, tomaremos al citado Reino, como modelo de desarrollo urbano ya consolidado y sometido a diversas reformas, y por lo tanto equiparable a un modelo urbanístico desarrollado.

Por otro lado, partiremos igualmente del modelo de la Ley colombiana 388 del año 1993, de ordenación territorial y sus sucesivas modificaciones con la existencia de los planes de ordenación territorial y los planes parciales así como un incipiente control ambiental como un modelo de ordenación urbana en vía de desarrollo, puesto que, tiene bastantes elementos normativos perfectamente homologables a las Naciones con planificación urbanas más desarrolladas, pero que por otra parte, carece de algunas fallas técnicas susceptibles de desarrollo o perfección y lógicamente de una consolidación general en cuanto al modelo por bastantes elementos de informalidad. Que no menoscaban al funcionamiento del sistema puesto que tiene un alto nivel de congregación jurídica en base no solo a la función social de la propiedad, si no, de la función ecológica pero que requieren de correcciones y desarrollos.

Y en tercer lugar, tomaremos de ejemplo la República Dominicana, que pese a las previsiones Constitucionales en relación con la limitación de la propiedad determinadas por la Carta Magna de 2010, carece de un modelo homogéneo al no tener a fecha de hoy aprobada una ley de ordenación territorial que permita una regulación y habilitación de los Planes de Ordenación Territorial y su desarrollo, el análisis de estos tres modelos pretende darnos un marco de comparación sobre los posibles modelos de ordenación urbana existentes en lberoamérica.

WPS RI-SHUR, no6, 2017, vol.2, ISSN: 2387-1768

MONOGRÁFICO SOBRE LAS ESTRATEGIAS DE DESARROLLO URBANO

SOSTENIBLE E INTEGRADO (EDUSI) 


\section{WPSReview International on Sustainable \\ Housing and Urban Renewal (RI-SHUR)}

Cabe en un apartado final analizar las determinaciones del Uruguay. Como país con más ferviente incorporación a su ordenamiento jurídico de los principios de la sostenibilidad en la ordenación urbana, al menos en la teoría.

Debe indicarse en esa línea recordarse que Naciones Unidas en su Conferencia Hábitat III, celebrada en Quito en octubre de 2016, aprobó la Nueva Agenda Urbana, que contribuirá a la aplicación de la Agenda 2030 para el Desarrollo Sostenible, la cual fija 17 Objetivos de Desarrollo Sostenible (ODS), de carácter integrado e indivisible que conjugan las tres dimensiones del desarrollo sostenible: económica, social y ambiental.

El Objetivo 13, Acción por el Clima, resalta la necesidad de adoptar medidas urgentes para combatir el cambio climático y sus efectos y poner en práctica el Acuerdo de París.

Que el VII programa de Acción Comunitaria en Materia de Medio Ambiente hasta 2020 persigue estimular los esfuerzos encaminados a contribuir a que las ciudades de la Unión Europea sean más sostenibles, concentrándose en la planificación medioambiental integrada, la movilidad sostenible, la calidad de vida y la salud pública. Con el fin de proteger la naturaleza y consolidar la capacidad de recuperación ecológica y de impulsar un crecimiento sostenible, hipocarbónico y eficiente en el uso de los recursos.

Que la Comisión Europea respalda el Pacto de los Alcaldes para el Clima y la Energía, que en 2015 amplió sus objetivos de reducción del $\mathrm{CO}_{2}$ al 40\% para 2030 e incluye la adaptación al cambio climático. El Pacto está abierto a todas las autoridades locales, independientemente de su tamaño y del estadio de implantación de sus políticas e materia de energía y clima.

\section{EL DERECHO URBANISTICO ESPAÑOL E IBEROAMERICANO.}

A la hora de analizar los modelos urbanísticos español, dominicano, uruguayo y colombiano desde una perspectiva comparada, hemos de hacer una breve introducción al régimen jurídico-administrativo de la nación española, en tanto en cuanto España en virtud del art. 137 de la Carta Magna de 1978, se articula como Estado descentralizado en tres niveles territoriales, el nivel nacional con unas competencias que tiene con carácter exclusivo tanto el gobierno como las Cortes Generales como poder legislativo, fundamentalmente recogidas en el art. 149 de la

WPS RI-SHUR, no6, 2017, vol.2, ISSN: 2387-1768

MONOGRÁFICO SOBRE LAS ESTRATEGIAS DE DESARROLLO URBANO

SOSTENIBLE E INTEGRADO (EDUSI) 


\title{
WPSReview International on Sustainable
}

\author{
Housing and Urban Renewal (RI-SHUR)
}

constitución, por otro lado el nivel autonómico de las comunidades autónomas, entidades homologables aunque con diferencias sustanciales a los estados federados en los países de naturaleza federal como la república brasileña o los Estados Unidos Mejicanos o los Estados Unidos de Norte América, que a diferencia de por ejemplo los departamentos colombianos gozan igualmente de dicha potestad legislativa $y$ finalmente el nivel local que carece de capacidades legislativas pero que tiene un importante ámbito y funciones de carácter ejecutivo especialmente en la materia que nos ocupa, que es la ejecución urbanística, en tanto en cuanto son las entidades competentes en materia de urbanismo.

La regulación derivada de esa particularidad organizativa del régimen legislativo del urbanismo en España se diferencia en dos ámbitos, por un lado la legislación básica en relación con el estatuto de la propiedad inmobiliaria vinculada al título competencial del art. 149.1.8 a de la Carta Magna, así como el régimen de responsabilidad y de la expropiación forzosa que le corresponde a las Cortes Generales y por tanto es igual en todo el territorio nacional y las que por otra parte, en relación con las técnicas sustantivas urbanísticas, las figuras del planeamiento, los instrumentos de equidistribución de beneficios y cargas del planeamiento, el régimen de la disciplina urbanística o de la intervención administrativa sobre el uso del suelo y la edificación, los patrimonios públicos del suelo, donde la regulación correspondiente de todas esas instituciones, compete en su legislación a las comunidades autónomas con carácter exclusivo, y por tanto excluyente de la legislación estatal, que en base a la determinación del art. 149.3 de la Constitución, tiene un carácter meramente supletorio de las comunidades autónomas, legislación además estatal que debe ser previa a la asunción con carácter exclusivo del título competencial en los diversos estatutos de autonomía.

Las competencias en materia urbanística en Colombia (al igual que en la República Dominicana y Uruguay), lógicamente se distribuyen de una manera muy diferente en España, en tanto en cuanto Colombia es un Estado unitario cuya descentralización territorial carece de potestades legislativas por parte de los departamentos de la república, puesto que tal y como señala la STC C-540 de 2001, Colombia es una "república unitaria descentralizada con autonomía de sus entidades territoriales" significando la definición constitucional tal y como apunta Younes Moreno ${ }^{1}$ la unidad es como el todo que necesariamente se integra por las partes y no la unidad como un bloque.

\footnotetext{
${ }^{1}$ YOUNES MORENO Diego. Curso de Derecho Administrativo. Editorial Temis S.A. Bogotá, 2004. $7^{\text {ạ }}$ edición. Pág. 79.
}

WPS RI-SHUR, no6, 2017, vol.2, ISSN: 2387-1768

MONOGRÁFICO SOBRE LAS ESTRATEGIAS DE DESARROLLO URBANO

SOSTENIBLE E INTEGRADO (EDUSI) 


\section{WPSReview International on Sustainable \\ Housing and Urban Renewal (RI-SHUR)}

En ese sentido igualmente el Tribunal Constitucional Colombiano, en su Stc. C-579 de 2001, indica que "......la autonomía no equivale a autarquía o soberanía de las entidades territoriales: debe entenderse como la concordancia de la actividad de estas con un órgano superior, que no rompe el modelo del Estado Unitario".

Por tanto las entidades territoriales colombianas, departamento, regiones, provincias y municipios tendrán competencias y funciones asignadas en la ley nacional no disponiendo de capacidades legislativas propias como así ocurre en las comunidades Autónomas españolas, para establecer modelos diferenciados urbanísticos con rango de ley.

Así, los departamentos gozan de competencias en materia de planificación conforme al art. 300 de la Constitución en sus apartados 2 y 3 establece:

2. Expedir las disposiciones relacionadas con la planeación, el desarrollo económico y social, el apoyo financiero y crediticio de los municipios, el turismo I el transporte, el ambiente, las obras públicas, las vías de comunicación y el desarrollo de sus zonas de frontera.

3. Adoptar acuerdo con la ley los planes y programas de desarrollo económico y social y los de obras públicas, con la determinación de las inversiones y medidas que se consideren necesarias para impulsar su ejecución y asegurar su cumplimiento.E igualmente el punto 8: las Asambleas de los departamentos tendrán capacidad para: "dictar normas de policía en todo aquello que no sea materia de disposición legal".

Por otro lado los concejos municipales, tienen conforme al art. 313 de la Constitución, la capacidad para: b) adoptar los correspondientes planes y programas de desarrollo económico y social y de obras públicas c) reglamentar los usos del suelo y, dentro de los limites que fije la ley, vigilar y controlar las actividades relacionadas con la construcción y enajenación de inmuebles destinados a vivienda i) dictar las normas necesarias para el control, la preservación y defensa del patrimonio ecológico y cultural del municipio.

Partiendo de esta distinción competencial debemos señalar que las leyes a aplicar serán siempre las estatales, pudiendo los departamentos y municipios aprobar planes y reglamentar usos siempre con estricta sujeción a la ley nacional, que además podrá ser objeto solo por la republica del correspondiente desarrollo reglamentario.

WPS RI-SHUR, no6, 2017, vol.2, ISSN: 2387-1768

MONOGRÁFICO SOBRE LAS ESTRATEGIAS DE DESARROLLO URBANO

SOSTENIBLE E INTEGRADO (EDUSI) 


\title{
WPSReview International on Sustainable
}

\author{
Housing and Urban Renewal (RI-SHUR)
}

\section{EL DERECHO URBANISTICO COLOMBIANO}

Partiendo de dicha distribución competencial y de la existencia de la ley nacional, podemos hablar de un derecho urbanístico colombiano, tal y como recoge SANTOFIMIO GAMBOA ${ }^{2}$ con unas características propias que suponen una reciente formación y que en el ámbito local gira en torno a los contenidos del plan de ordenamiento territorial. Ahora bien, ese derecho urbanístico colombiano parte de una regulación constitucional previa que como afirma GALVIS GAITÁN ${ }^{3}$ establece un ordenamiento constitucional del territorio municipal, puesto que los artículos 51, 58 párrafo $2^{\circ}$ y $3^{\circ}$, 82 y $313.3,339$ párrafo $2^{\circ}$ de la Carta Magna disponen un ordenamiento territorial municipal, al recoger entre otras cuestiones la función social de la propiedad con las obligaciones que ello conlleva: la institución expropiatoria, el deber del Estado de aprobar planes de vivienda de interés social y de velar por la protección de la integridad del espacio público, por su destino al uso común, el cual prevalece sobre el interés particular, por la regulación de la utilización del suelo y del espacio aéreo y urbano, por el control de las actividades de construcción y enajenación de inmuebles para vivienda y por la utilización de plusvalías para establecer planes de desarrollo y territoriales.

Pero no es objeto de este estudio la determinación y análisis de todo el derecho urbanístico colombiano, que fundamentalmente se regula en la Ley 388 de 1997, ni hablar de la zonificación en la planificación, sino de la ejecución de los planes, esto es, la concreción en la realidad tanto técnica como jurídica de las determinaciones previstas en la previa planificación.

La ley 388 de 1997 fue expedida como una reforma de la ley novena de 1989, en su elaboración se afirma una preocupación por el tema de ordenamiento o planeación territorial, traduciéndose en una reivindicación del mismo articulado, a la gestión, y junto al desarrollo económico y social, como instrumentos inspirados en la ley del suelo española.

Se prevé un sistema de planeación a la manera de planes que se articula con la gestión del suelo de manera que dependen entre si, siendo los primeros I base para la aplicación de los instrumentos de gestión que permite cumplir los objetivos del ordenamiento. Los planes concretan, objetivos, directrices, mecanismos de distribución de las cargas y beneficios urbanísticos, así como las normas urbanísticas

\footnotetext{
${ }^{2}$ SANTOFIMIO GAMBOA Jaime Orlando "Derecho urbanístico". Bogotá. Universidad Externado de Colombia. 2004. Págs. 36 a 44.

${ }^{3}$ GALVIS GAITÁN Fernando "EI municipio colombiano". 4ª Edición. Themis. Bogota 2007. Págs 120.
}

WPS RI-SHUR, no6, 2017, vol.2, ISSN: 2387-1768

MONOGRÁFICO SOBRE LAS ESTRATEGIAS DE DESARROLLO URBANO

SOSTENIBLE E INTEGRADO (EDUSI) 


\section{WPSReview International on Sustainable \\ Housing and Urban Renewal (RI-SHUR)}

ya no concebidas de manera estática sino como los elementos centrales de dicho sistema, porque son las que concretan los aprovechamientos urbanísticos en términos de índices de edificabilidad. La articulación entre el sistema de planeación y de gestión esta dada por los principios que estructuran la ley y por las decisiones de carácter político.

Partiendo de la ley 388 de 1997 debemos destacar los siguientes principios:

1. La función social y ecológica de la propiedad.

2. La prevalecía del interés público sobre el particular.

3. El urbanismo como función publica.

4. La distribución equitativa de las cargas y beneficios.

5. Participación democrática.

Los deberes impuestos a la propiedad son:

a. La obligación de urbanizar y construir en los tiempos y bajo las condiciones definidos por los instrumentos de ordenamiento territorial.

b. Traslado a la colectividad de la tierra correspondiente a áreas libres de recreación, redes e infraestructuras y equipamientos colectivos.

c. Obligación de obtener licencia aun para loteos subdivisiones o parcelaciones.

d. Deber de participar a la colectividad de un porcentaje de los incrementos de los precios del suelo producido por las decisiones del planeamiento o por la ejecución de obras públicas.

e. Deber de conservar el patrimonio arquitectónico, histórico y ambiental.

Estos principios generales y deberes se traducen además en las siguientes premisas:

1. El derecho de urbanizar y de construir no esta incorporado per se en el derecho de propiedad sino que es un derecho que se adquiere en la medida e que se asuman las cargas a favor de la colectividad determine el plan. Más que simples limitaciones a la propiedad se trata de una redefinición profunda de su contenido la que se ha producido en nuestro país, ya que condiciona el ejercicio de los derechos urbanísticos a la asunción de cargas, en lugar de una asignación de normas de manera general contenida en los planes de ordenamiento o los códigos de urbanismo.

2. El Plan de Ordenamiento Territorial Colombiano, que es adoptado a nivel municipal, es un plan vinculante, es decir, que define derechos y deberes tanto de la administración municipal como de los propietarios y, por tanto, concreta el régimen

WPS RI-SHUR, no6, 2017, vol.2, ISSN: 2387-1768

MONOGRÁFICO SOBRE LAS ESTRATEGIAS DE DESARROLLO URBANO

SOSTENIBLE E INTEGRADO (EDUSI) 


\title{
WPSReview International on Sustainable
}

\author{
Housing and Urban Renewal (RI-SHUR)
}

urbanístico de la propiedad hasta el punto de definir el contenido patrimonial de la misma.

3. No hay lugar a patrimonialización por efecto de las normas generales, en tanto, sólo se concretan o consolidan derechos urbanísticos, previa la asunción de las cargas que definan la ley y el plan de ordenamiento territorial

Así debe destacarse que en la Ley 388/1997, norma de cabecera del ordenamiento territorial Colombiano no se concretan técnicas ni instrumentos para plasmar en la realidad un cumplimiento de los principios del desarrollo sostenible, pero que la Constitución colombiana y los grandes principios legales si se ajustan a ese marco de objetivos, en gran medida.

\section{EL DERECHO URBANÍSTICO EN REPÚBLICA DOMINICANA}

Cabe empezar afirmando que para elaborar cualquier argumentación sobre el derecho territorial en general y urbanístico en particular de la Republica Dominicana, deberemos de acudir en primer lugar en virtud de las determinaciones lógicas de cualquier ordenamiento jurídico basado en la jerarquía normativa, a la norma máxima de dicha República, esto es, la Constitución Dominicana dada en Santo Domingo distrito nacional en 2010, y en ese sentido, al ser una Constitución todavía reciente incorpora en buena medida las determinaciones y sensibilidades de carácter ambiental hidrológico y de derechos sociales que en los tiempos actuales devengan con carácter general con respecto a dicho ordenamiento territorial, por lo menos hasta julio de 2010 fecha de la aprobación de la citada constitución.

La sensibilidad ambiental y la reserva de estado de recursos naturales el carácter demanial de los recursos hídricos y la existencia de áreas protegidas se recogen expresamente en los artículos 14 a 17 de la Constitución regulándose los aprovechamientos de los recursos naturales en el artículo 17, esto es, una ubicación importantísima dentro del título I, referida a la nación de los estados de su gobierno y de sus principios fundamentales, no mete una incorporación en derechos y deberes o en principios rectores o en la regulación de la economía como otras muchas constituciones que incorporan sus determinaciones lo realizan.

Los preceptos generales dirigidos con carácter más sustantivo hacia el mundo inmobiliario y urbanístico, los encontramos en la Sección II del Capítulo I, sobre los derechos fundamentales englobada en el Título II de los derechos garantías y deberes

WPS RI-SHUR, no6, 2017, vol.2, ISSN: 2387-1768

MONOGRÁFICO SOBRE LAS ESTRATEGIAS DE DESARROLLO URBANO

SOSTENIBLE E INTEGRADO (EDUSI) 


\section{WPSReview International on Sustainable \\ Housing and Urban Renewal (RI-SHUR)}

fundamentales diferenciándose de la Sección I de los derechos civiles y políticos, que aunque se denominan bajo la característica común de derechos fundamentales, podemos entender que serían equiparables en nuestro ordenamiento jurídico español a los derechos y deberes, o a los principios rectores aunque la garantía es mayor recogiéndose no obstante un régimen de garantías específico para estos, aunque el artículo 68 de la Constitución Dominicana garantiza la efectividad de los derechos fundamentales a través de los mecanismos de tutela o protección que ofrecen a la persona la posibilidad de obtener la satisfacción de sus derechos frente a los sujetos obligados o deudores de los mismos, vinculando a los poderes públicos, los poderes los cuales den garantizar su efectividad los términos establecidos por la constitución y por la ley.

Existiendo una acción de amparo, prevista en el artículo 72, que no diferencia, dentro de los derechos fundamentales, a los civiles de los económicos sociales, incluso de los deportivos y culturales, ni del cuarto poder derechos fundamentales que son los derechos productivos y de medio ambiente.

Así debemos destacar dentro de este segundo grupo de derechos económicos y sociales junto a la libertad de empresa que recoge junto al derecho, capacidad para recrear y organizar empresas, sin más limitaciones que las previstas por las constituciones que establezcan las leyes, la posibilidad de administrado tiene que dictar medidas para regular la economía y promover las actuaciones de actividad impulsar el desarrollo integral del país. Junto a ello debemos señalar el derecho a la propiedad, pero con una función social que implica obligaciones de interés social la dedicación de las fincas a fines útiles incluso en grado del latifundio.

El derecho específico a la vivienda se recoge en el artículo 59 de la Constitución, señalándose que toda persona tiene derecho a una vivienda digna, con servicios básicos esenciales, el estado deberá fijar las funciones necesarias para hacer efectivo este derecho y promover los planes de viviendas y asentamiento humanos de interés social.

El acceso legal a la propia inmobiliaria titulada es una prioridad fundamental de las políticas públicas de la promoción de vivienda.

Las determinaciones se complementan como ya hemos señalado en derechos colectivos y del medio ambiente, recogidos en el artículo 66 y 67 de la Constitución, con conservación de equilibrio ecológico, protección del medio ambiente y la

WPS RI-SHUR, no6, 2017, vol.2, ISSN: 2387-1768

MONOGRÁFICO SOBRE LAS ESTRATEGIAS DE DESARROLLO URBANO

SOSTENIBLE E INTEGRADO (EDUSI) 


\title{
WPSReview International on Sustainable
}

\author{
Housing and Urban Renewal (RI-SHUR)
}

preservación del patrimonio cultural, histórico, urbanístico, artístico, arquitectónico, y arqueológico.

Las citadas funciones sobre el patrimonio histórico, le corresponde al Congreso Nacional conforme a lo dispuesto en el artículo 93.1 c) de la Constitución.

Todas las determinaciones recogidas en el Titulo IX, de la constitución, sobre ordenamiento del territorio y de la Administración Local, debe destacarse lo previsto en el artículo 194 sobre un plan de ordenamiento territorial, en el cual se atribuye como prioridad del estado, la formulación y ejecución mediante ley de un plan de ordenamiento territorial, que asegure el uso eficiente y sostenible de los recursos naturales de la nación, acorde con la necesidad de adaptación al cambio climático.

Actualmente debe recordarse la importancia en el conjunto del derecho territorial dominicano, las determinaciones recogidas en el Título XI, de la Constitución, sobre Régimen Económico Financiero y de la Cámara de Cuentas, y así en ese sentido el artículo 217 sobre orientación y fundamento establece la orientación del régimen económico hacia la búsqueda del desarrollo humano fundamentándolo en el crecimiento económico, la redistribución de la riqueza, la justicia social, la equidad, la eclosión social y territorial, y la responsabilidad ambiental, todo ello en un marco de libre competencia, igualdad de oportunidades, responsabilidad social, participación y solidaridad, como consecuencia de ello se establece en el artículo 218 , la necesidad de un crecimiento sostenible, puesto que la iniciativa privada libre debe junto con el estado procurar un crecimiento equilibrado y sostenible de la economía, manteniendo equilibrio precios, y con una utilización racional de los recursos disponibles, así el reconocimiento de iniciativa privada, bajo un principio de subsidiariedad del estado, debe ser reconocido expresamente en el artículo 219.

No obstante se recoge expresamente en la planificación en los artículos 241 y 242 de la Carta Magna. En dicho Título XI, pero dentro de la Sección II del Capítulo II, de las Fianzas Públicas de la Planificación.

Así, en la estrategia de desarrollos debe aprobarse mediante el Congreso Nacional mediante la ley correspondiente, que regulará el proceso de planificación existiendo un plan nacional plurianual del sector público con sus correspondientes actualizaciones, de la segunda legislatura del año en que se inicia el periodo del gobierno con obligación de remitirse.

WPS RI-SHUR, no6, 2017, vol.2, ISSN: 2387-1768

MONOGRÁFICO SOBRE LAS ESTRATEGIAS DE DESARROLLO URBANO

SOSTENIBLE E INTEGRADO (EDUSI) 


\section{WPSReview International on Sustainable \\ Housing and Urban Renewal (RI-SHUR)}

Desde un punto de vista estrictamente municipal, la ordenación territorial y la regulación jurídica del urbanismo se debe centrar las determinaciones de la Ley 1772007, del Distrito Nacional y los Municipios, la cual fue aprobada por el Congreso Nacional, y que dedica su Título IX a la Planificación y Gestión Municipal, con dos capítulos, dedicado a la Planificación Municipal, y el dedicado a la Gestión Ambiental Municipal.

Así, el artículo 122 de la citada Ley 177-07, se ocupa de los Planes Municipales de desarrollo, atribuyéndose la capacidad para aprobar y no capacidad puesto que se utiliza un término imperativo, aprobarán, de los Planes Municipales de desarrollo, la cual será a iniciativa de los síndicos y con participación de la comunidad.

Dichos Planes tienen como determinación establecer una utilización de la inversión adecuados a los recursos municipales, propulsado en el desarrollo equitativo y sostenible, así como un ordenamiento racional del territorio.

A tal fin la elaboración del I Plan Municipal de desarrollo se debe efectuar por el Consejo municipal.

Planificación de carácter municipal, tras su coordinación con las de carácter nacional y sectorial incluso nacionales, las cuales, a los efectos de planificación pública deben de garantizar la participación de los ayuntamientos, tanto si son nacionales, provinciales, regionales, municipales, etc.

Por otra parte, es obligado la existencia de oficinas municipales de planificación y programación entre cuyos fines estarán los de garantizar la coordinación, integración de las planificaciones sectoriales, con las municipales así como la valoración de resultados de la gestión. $E$ igualmente oficinas de planeamiento urbano, por cada ayuntamiento cuyo objetivo central será asistencia técnica entre el ayuntamiento y las comunidades en el diseño, elaboración y ejecución de los planes de desarrollo del municipio y gestionar el planeamiento urbanístico, uso del suelo y edificación en las áreas urbanas y rústicas del territorio municipal, desde criterios de inclusión y equidad.

Así, en cualquier caso, los ayuntamiento deben disponer la formación coordinada de los planes de desarrollo, con los planes y programas de desarrollo regional, provincial y nacional, en cualquier caso para municipios que no tengan posibilidad de tener su oficina de planeamiento urbanístico, deben de hacerlo coordinados o asociados con otros municipios contando la asistencia de los órganos sectoriales correspondientes.

WPS RI-SHUR, no6, 2017, vol.2, ISSN: 2387-1768

MONOGRÁFICO SOBRE LAS ESTRATEGIAS DE DESARROLLO URBANO

SOSTENIBLE E INTEGRADO (EDUSI) 


\section{WPSReview International on Sustainable \\ Housing and Urban Renewal (RI-SHUR)}

Partiendo de esta regulación constitucional y de las normativas legales en desarrollo de la misma el derecho de la organización territorial y el urbanismo de la República Dominicana se articula, al igual que el Español, en torno a la ciudad del plan, esto es a la planificación de la ordenación urbana, siendo el plan la figura central tal y como hemos visto desde cualquier municipio o a nivel supramunicipal, puesto que las oficinas técnicas correspondientes para la planificación urbana que deben existir en cada municipio deberán asesorar a las diferentes corporaciones municipales para el diseño y ordenación de sus términos territoriales.

Partiendo de esa circunstancia, debemos destacar, que el planeamiento urbanístico es la técnica de diseño de la ordenación territorial en cada término municipal con un carácter normativo, esto es, dibujos o voluntades de consecución de objetivos que tienen carácter normativo y que vinculan tanto a los poderes públicos como a las entidades particulares.

Así la planificación urbanística y territorial, puede ser muy diversa, en primer lugar, partiendo del tamaño del ámbito a planificar desde la región la provincia o el municipio, partiendo de realidades metropolitanas o meras poblaciones urbanas o la ordenación de poblados menores, así por otra parte debemos destacar la diferenciación entre la zonificación, frente a la planificación basada en la forma preexistente puesto que por ejemplo una ciudad histórica, un casco ya consolidado protegido constitucionalmente desde el punto de vista cultural, es muy difícil proceder a una transformación radical, sin perjuicio de que se puedan realizar actuaciones planificadoras de renovación urbana.

Por otro lado, esta el Transecto Urbano -rural, entre las zonas de carácter puramente urbano y las zonas preservadas o protegidas como ámbitos naturales, existiendo un término intermedio sobre zonas rurales en las cuales no se podrá permitir la urbanización con carácter general, pero sí determinados usos y establecimientos humanos.

Igualmente a la hora de plantear una planificación urbanística existen multitud de modalidades de ordenación urbana y así, un crecimiento disperso con edificación unifamiliar aislada y zonas verdes, o un crecimiento compacto mediante bloques y manzanas cerradas, todo ello sin perjuicio de las correspondientes y necesarias dotaciones de zonas verdes equipamientos públicos, escolares, sanitarios, administrativos y culturales.

WPS RI-SHUR, no6, 2017, vol.2, ISSN: 2387-1768

MONOGRÁFICO SOBRE LAS ESTRATEGIAS DE DESARROLLO URBANO

SOSTENIBLE E INTEGRADO (EDUSI) 


\section{WPSReview International on Sustainable \\ Housing and Urban Renewal (RI-SHUR)}

Igualmente la libertad de planificación dentro de los conceptos urbanos tiene que tener unos límites lógicos, no solo la ley y el texto constitucional, sino también, en realidades físicas, y subrayables por ejemplo, las zonas sometidas a riesgos naturales, ya sean de carácter sísmico o inundaciones hidrológicas u otros aspectos, que deben de tenerse en cuenta a la hora de diseñar no pudiéndose obviar la realidad física salvo consecuencias imprevisibles.

A la hora de tener en cuenta una Planificación debemos de distinguir la existencia de diversas tipologías Planificadoras, sectoriales, territoriales, y urbanísticas como posteriormente veremos, que tal y como se recoge en la guía para la conducción de procesos de ordenamiento territorial ${ }^{4}$, podemos diferenciar entre los siguientes tipos:

a) Planes locales de desarrollo, y planes estratégicos municipales.

b) Planes directores, planes municipales de ordenamiento territorial, planes reguladores y planes urbanísticos.

c) Planes sectoriales y planes transversales.

d) Los planes operativos anuales y multianuales.

Partiendo de esta circunstancia, vamos a proceder lógicamente a un análisis de los conceptos de planificación en sí misma para posteriormente analizar la planificación territorial y general urbanística desde el punto de vista de la legislación española.

\section{MARCO JURÍDICO DEL URUGUAY EN LA MATERIA}

\section{Introducción y evolución histórica}

La república oriental del Uruguay mediante la Ley № 18.308 sobre ordenamiento territorial y desarrollo sostenible, marco regulador general, de 18 de junio de 2008 estableció un régimen jurídico específico de lo que en España se conoce por ordenación territorial y urbanismo.

Con carácter previo en Uruguay las Leyes de Indias mantuvieron su vigencia, al menos teórica, hasta 1877. Entonces se adoptó el decreto que estableció el reglamento "para el trazado de nuevos pueblos y colonias en el territorio de la República". Desde un punto de vista conceptual este nuevo reglamento representó un claro retroceso en relación a las primeras, particularmente por su restringida visión del

${ }^{4}$ Guía para la conducción de procesos de ordenamiento territorial Ademuca 2009.

WPS RI-SHUR, no6, 2017, vol.2, ISSN: 2387-1768

MONOGRÁFICO SOBRE LAS ESTRATEGIAS DE DESARROLLO URBANO

SOSTENIBLE E INTEGRADO (EDUSI) 


\title{
WPSReview International on Sustainable
}

\author{
Housing and Urban Renewal (RI-SHUR)
}

ordenamiento territorial. Se perdió la riqueza del concepto de ciudad-territorio, así como los distintos estatutos sobre el uso y la propiedad que lo caracterizaron. En efecto, la organicidad del concepto indiano, donde el clima, la salubridad, la producción o la forma son aspectos de un mismo problema, desapareció en favor de una idea del territorio que se focaliza exclusivamente en la ciudad. La colonización del territorio dejó de ser un proyecto de naturaleza socio-cultural, vinculado a un saber que provenía de la experiencia y de la dimensión concreta de sus desafíos, fueran estos políticos o físicoterritoriales, para convertirse en una serie de prescripciones geométricas que pretendían habilitar el crecimiento infinito de las ciudades. El Reglamento de 1877 "fracasó en el intento de imponer un trazado único geométrico abstracto, sustitutivo del tradicional, y también en la pretensión de establecer un método de conducción del crecimiento orgánico de los pueblos. En efecto, muy pocos núcleos urbanos se ciñeron a su trazado y ninguno desarrolló su crecimiento por los mecanismos que preceptuaba" Probablemente la poca fortuna del nuevo reglamento haya sido la mejor.

En 1859 el presidente G. Pereira atribuía funciones urbanísticas a las Juntas Económicas Administrativas, apoyándose en "las disposiciones legales que rigen la materia y son las consignadas en las leyes llamadas de Indias "expresión del espíritu liberal que lo animaba. En este sentido, "el no cumplimiento de las prescripciones se debe fundamentalmente a la inadecuación del modelo a los intereses de los especuladores de tierra, a causa de las dimensiones otorgadas al espacio público (plaza y calles), que disminuye la rentabilidad del fraccionamiento. El incumplimiento es avalado por la aprobación por parte de los organismos competentes, de nuevos pueblos transgresores del modelo ${ }^{7 "}$ El decreto de 1877 dio inicio a una tradición nacional muy consolidada que afirmó en la inobservabilidad de las leyes territoriales el mecanismo básico de su ordenamiento real. Esta tradición, con mecanismos y argumentos similares, ha sobrevivido ininterrumpidamente hasta nuestro días*.

La Ley de Centros Poblados, aprobada en 1946, sustituyó al Reglamento de 1877. Puede considerarse la conclusión de una largo proceso donde la formación y transformación del territorio, tradicionalmente asociados a la iniciativa privada y al mercado, se convirtieron en una preocupación de interés general necesariamente vinculada a una activa participación reguladora del estado. Se trató de una ley moderna en términos técnicos, sin dudas progresista en su afán de transformar la

\footnotetext{
${ }^{5}$ ÁLVAREZ LENZI, , Ricardo: Fundación de poblados en Uruguay, Montevideo, Farq-UdelaR, 1986. Pág 36, 1986

${ }^{6}$ BARACCHINI, H. y ALTEZOR, C. (2008): Historia del ordenamiento territorial en el Uruguay, Montevideo, Trilce 82). Pág 5.

${ }^{7}$ CARMONA, L. y GÓMEZ, M.L. (1999): "Montevideo, proceso planificador y crecimientos", Montevideo, Farq-UdelaR. 28).
}

WPS RI-SHUR, no6, 2017, vol.2, ISSN: 2387-1768

MONOGRÁFICO SOBRE LAS ESTRATEGIAS DE DESARROLLO URBANO

SOSTENIBLE E INTEGRADO (EDUSI) 


\title{
WPSReview International on Sustainable
}

\author{
Housing and Urban Renewal (RI-SHUR)
}

construcción real de los territorios, particularmente los urbanos. Fomentaba la formación de centros urbanos apoyados en estudios profundos del territorio (desde la topografía o la naturaleza geológica del suelo considerado hasta las necesidades infraestructurales o de equipos sociales requeridos por su adecuado ordenamiento), no imponía modelos formales preconcebidos y se proyectaba tanto a los territorios existentes como a su transformación futura. Sin embargo, ya en su proceso de concreción legislativa se generaron los mecanismos para su inobservancia real, evidenciando de manera temprana las dificultades para hacer del territorio algo más que un mero negocio especulativo. Su ignorancia en los departamentos vecinos a la capital produjo efectos territoriales decisivos, y a la vez inesperados, que aun hoy determinan uno de los problemas más trascendentes del ordenamiento del territorio en nuestro país, como es el desarrollo y la expansión descontrolada del área metropolitana montevideana.

Su experiencia, sin duda, debe evaluarse a la luz de las difíciles aunque ineludibles relaciones entre política y ordenamiento territorial. Aunque no sólo. Porque también proyectó una visión del territorio como objeto novedoso, no acumulativo, y a la vez capaz de regenerarse a través de su mera pertinencia técnica, que se demostró inoperante. Su voluntarismo técnico, en realidad, no estaba muy alejado de cierto optimismo moderno asociado a la supuesta inevitabilidad del progreso y a la idea de la tabla rasa. "Debe reconocerse que no se lograron los resultados que con su sanción se perseguían. El proceso fundacional, con posterioridad al año 1946, en la generalidad de los casos no acusa diferencias respecto a las características que presentaba con anterioridad a la puesta en vigencia de la ley. La iniciativa fundacional continuó a cargo del sector privado que se condujo como antes tras el exclusivo objetivo de la obtención de lucro... Se continúa loteando tierras que muchas veces no son aptas para el establecimiento de un pueblo, y también otras que estando en explotación agrícola, su desafectación a ese uso para darle destino urbano, apareja un grave perjuicio para la economía general del país. Además se sigue procediendo por retaceo de dotación de instalaciones y servicios públicos, los más indispensables, a los núcleos urbanos creados" (Álvarez Lenzi, 41*). La década de los 70 marcó una inflexión que dio inicio a profundas transformaciones en la sociedad uruguaya. Estos procesos de cambio no fueron indiferentes, en particular, para los territorios urbanos. Por el contrario, tuvieron consecuencias trascendentes y desencadenaron trayectorias que caracterizan fuertemente nuestra realidad socio-territorial presente.

Probablemente en julio de 1974, con la aprobación de la nueva Ley de Alquileres (en realidad llamada de Arrendamientos Urbanos), pueda ubicarse el corte simbólico entre un antes y un después en nuestra problemática territorial. En primera instancia esta ley introdujo la libre contratación en materia de alquileres, desmantelando cualquier atisbo

WPS RI-SHUR, no6, 2017, vol.2, ISSN: 2387-1768

MONOGRÁFICO SOBRE LAS ESTRATEGIAS DE DESARROLLO URBANO

SOSTENIBLE E INTEGRADO (EDUSI) 


\title{
WPSReview International on Sustainable
}

\author{
Housing and Urban Renewal (RI-SHUR)
}

de protección social en relación a los inquilinos. Con ello, sin embargo, consolidó un proceso que tuvo diversas y profundas consecuencias en múltiples problemáticas que de una manera $u$ otra conciernen al territorio y sus ordenamientos (transformaciones urbanas, políticas de inversión pública en la materia, valores del suelo, déficit de vivienda, fragmentación socio-urbana, etc.). Los impactos socio-territoriales de esta ley en el largo plazo fueron decisivos. Sintéticamente pueden visualizarse, claramente en el caso montevideano, a través de un proceso que tiene dos caras, a la vez distintas y complementarias. Por un lado el vaciamiento sostenido de las áreas urbanas consolidadas y servidas, que desde entonces o se ha mantenido o se ha profundizado. Por el otro, la consolidación estructural de una expansión periférica creciente que extiende la mancha urbana de manera irracional y a la vez imparable. Sin mayores crecimientos poblacionales, el área metropolitana tuvo una expansión 7 que además no fue respaldada por inversiones en infraestructuras, servicios, equipamientos sociales, etc. El déficit de vivienda se profundizó notablemente y las estrategias informales se convirtieron en regla de la expansión metropolitana.4 La fragmentación social asociada a tal proceso terminó por consolidar una territorialización de la sociedad según sus posibilidades de consumo. Comenzó la sustitución del barrio por el gueto y el territorio se convirtió en el mejor aliado de una sociedad cada vez más fragmentada y distante.

\section{Régimen jurídico vigente}

Por lo que se refiere a la normativa vigente, tras la aprobación parlamentaria de la Ley 18.308, de Ordenamiento Territorial y Desarrollo Sustentable ${ }^{8}$, debe reseñarse que esta Ilenó un vacío que la creación del Ministerio de Vivienda Ordenamiento Territorial y Medio Ambiente, en 1990, hacía aun más evidente. La ley aprobada no es una ley marco que simplemente proponga grandes orientaciones en la materia. Por el contrario, se trata de una ley exhaustiva y sumamente precisa en sus disposiciones. Consta de 83 artículos ordenados en 8 títulos que definen, entre otros, los fines y la naturaleza del ordenamiento territorial, los derechos y deberes territoriales de las personas y de la propiedad inmueble, los instrumentos de la planificación en sus diversas escalas, los criterios generales que ordenan los usos de suelo y controlan su sostenibilidad y los mecanismos de participación social y de coordinación institucional. Las novedades que presenta la nueva ley en relación al marco jurídico nacional son trascendentes. Interesa señalar cuatro aspectos básicos: la definición del ordenamiento territorial como una función pública -que se materializa en un conjunto

\footnotetext{
${ }^{8}$ Sobre esta vid URRUZOLA. Juan Pedro" A propósito de la nueva Ley de Ordenamiento Territorial y sus directrices nacionales" Págs 107 a 121 de la Revista Pampa n 5, 2009.
}

WPS RI-SHUR, no6, 2017, vol.2, ISSN: 2387-1768

MONOGRÁFICO SOBRE LAS ESTRATEGIAS DE DESARROLLO URBANO

SOSTENIBLE E INTEGRADO (EDUSI) 


\title{
WPSReview International on Sustainable
}

\author{
Housing and Urban Renewal (RI-SHUR)
}

de acciones transversales cuya finalidad es la mejora de la calidad de vida de la población, la integración social en el territorio y el uso sustentable de los recursos naturales y culturales- la incorporación del conjunto del territorio -urbano, rural y marítimo- en los procesos de planificación territorial- la regulación del ejercicio de los derechos de propiedad sobre el suelo en función del interés general-que se desprende de los objetivos perseguidos por la propia Ley- la introducción de un nuevo instrumento de planificación territorial a escala nacional -capaz de potenciar una lógica proyectual desconocida hasta ese momento en el acervo cultural territorial tradicional del Uruguay.

Partiendo de ese marco jurídico básico debemos destacar que la figura clave son las llamadas Directrices Nacionales de Ordenamiento Territorial, reguladas en el segundo Capítulo del tercer Título de la Ley de Ordenamiento Territorial y Desarrollo Sostenible, donde se determinan los instrumentos previstos en el ámbito nacional y regional para la planificación y ejecución de la misma.

Las Directrices Nacionales, en particular, "constituyen el instrumento general de la política pública en la materia". Se trata, de acuerdo al artículo diez, del único instrumento de ordenación cuya elaboración corresponde al Poder Ejecutivo y cuya aprobación es potestad del Poder Legislativo. Tanto el concepto como los procedimientos propuestos para la definición de las Directrices Nacionales ponen en evidencia la trascendencia asignada por la Ley a dicho instrumento. Las Directrices Nacionales exigen una visión integral y unitaria del territorio nacional que debe asociarse estrechamente con las múltiples aproximaciones parciales del mismo, tanto en términos regionales como en términos sectoriales y tanto en términos nacionales como internacionales. Su alcance, por lo tanto, las transforma en el instrumento privilegiado de una visión proyectual de largo plazo que, es bueno recordarlo, nunca existió de manera explícita en la historia de las políticas públicas nacionales. Los ámbitos de elaboración y aprobación propuestos para las Directrices evidencian que en la visión de la Ley un proyecto de largo plazo para el territorio nacional no es meramente un desafío técnico. Su construcción política, en este sentido, parece una perspectiva de trabajo imprescindible para que el mismo trascienda su condición meramente teórica y se convierta en un instrumento de transformación real de nuestro territorio.

\section{La plasmación de los principios de desarrollo sostenible}

Específicamente en relación al ordenamiento territorial y el desarrollo sostenible, en 2008, el parlamento uruguayo aprobó la indicada ley 18.308. En la exposición de

WPS RI-SHUR, no6, 2017, vol.2, ISSN: 2387-1768

MONOGRÁFICO SOBRE LAS ESTRATEGIAS DE DESARROLLO URBANO

SOSTENIBLE E INTEGRADO (EDUSI) 


\title{
WPSReview International on Sustainable
}

\author{
Housing and Urban Renewal (RI-SHUR)
}

motivos del Proyecto de Ley de Ordenamiento Territorial y Desarrollo Sostenible (LOTDS, 2008) se menciona que: “(...) La planificación para el desarrollo territorial sostenible se funda en el establecimiento de un claro régimen jurídico para el territorio."

La ley aprobada en su artículo 4 "Materia del Ordenamiento Territorial" establece que: "El ordenamiento y desarrollo territorial sostenible comprende: a) La definición de estrategias de desarrollo sostenible, uso y manejo del territorio en función de objetivos sociales, económicos, urbanísticos y ecológicos, a través de la planificación. (...) c) La identificación y definición de áreas especiales de protección, por su interés ecológico, patrimonial, paisajístico, cultural y de conservación del medio ambiente y los recursos naturales. d) La identificación de zonas de riesgo por laexistencia de fenómenos naturales o de instalaciones peligrosas y asentamientos humanos vulnerables (...)". Las citas precedentes evidencian varios aspectos relevantes, entre los que se destaca la incorporación de la dimensión ecológica en la materia del ordenamiento territorial y específicamente "La identificación y definición de áreas especiales de protección, por su interés ecológico, patrimonial, paisajístico, cultural y de conservación del medio ambiente y los recursos naturales".

El Decreto 221-009 derivado de la LOTDS y que la desarrolla, define el Informe Ambiental Estratégico, que supone identificar las problemáticas que son de especial relevancia en la materia ambiental para la elaboración de objetivos específicos, cursos de eventos (estrategias) y toma de decisiones de actuación, en el contexto de un proceso de gestión planificada. El objetivo es que los aspectos ambientales y la calidad del hábitat, sean evaluados desde las primeras fases de la preparación de planes urbanos (entre otros ámbitos territoriales de actuación).

La LOTDS, reconoce una especial protección a los suelos rurales, a través de restricciones a su transformación, en especial hacia modalidades de uso u ocupación diferente a las de producción agropecuaria o extractiva "pura" (Art.31). La propia clasificación del suelo rural es un instrumento de protección específica, clasificándolo en 2 subcategorías: a) rural productivo y b) rural natural (con el fin de mantener el medio natural, y proteger el medio ambiente en general). En un apretado resumen de las normas analizadas, se destacan por su significación y por su relacionamiento conceptual y potencialmente sistémico-operativo: La Constitución de la República Oriental del Uruguay en su artículo 47 establece: "La protección del medio ambiente es de interés general" y que "La política nacional de aguas y saneamiento estará basada en: a) el ordenamiento del territorio, conservación y protección del Medio Ambiente y la restauración de la naturaleza". La Ley General Protección del Medio Ambiente (LGPA,

WPS RI-SHUR, no6, 2017, vol.2, ISSN: 2387-1768

MONOGRÁFICO SOBRE LAS ESTRATEGIAS DE DESARROLLO URBANO

SOSTENIBLE E INTEGRADO (EDUSI) 


\title{
WPSReview International on Sustainable
}

\author{
Housing and Urban Renewal (RI-SHUR)
}

№ 17.283) institucionaliza el principio precautorio, y la prevención y previsión como criterios prioritarios, sumado a la presunción de daño como suficiente para adoptar medidas de protección. En su artículo 7 establece los instrumentos de gestión ambiental, incluyendo los Estudios de Impacto Ambiental (EsIA) y los procesos de autorización correspondientes. Por vía de interpretación legítima la LGPA definió como "daño grave" al ambiente (concepto adjetivado incluido en el artículo 47 de la Constitución), a aquellos impactos que superen los parámetros admitidos por las normas de referencia. Si bien establecer límites cuantitativos a la contaminación u otras afectaciones ambientales es un criterio que debería ser modificado en función del conocimiento de los ecosistemas, los servicios ambientales, sus sinergias, las redes tróficas y sus presiones-respuestas, hoy aportan un marco de referencia para establecer parámetros medibles de impacto ambiental. Esos indicadores están disponibles o pueden construirse, y de allí el Informe Ambiental Estratégico debería tomar los valores de referencia para aplicar a los factores que definen su modelo territorial. La Ley de Evaluación de Impacto Ambiental (№ 16.466) y su reglamentación (Decreto 435/94) establecen el régimen de Evaluación de Impacto Ambiental, aplicable a la ejecución de ciertos proyectos que requerirán Autorización Ambiental Previa que otorgará (o no) el Ministerio de Vivienda Ordenamiento Territorial y Medio Ambiente. La Ley sobre Políticas Nacional de Aguas (№ 18.610/2009) establece los principios rectores para la gestión de los recursos hídricos, de los que se destacan por su interés general: 1) la gestión sustentable y solidaria con las generaciones futuras de los recursos hídricos y 2) la preservación del ciclo hidrológico. La gestión integrada de los recursos hídricos deberá contemplar entre otros aspectos la cuenca hidrográfica como unidad de actuación para la planificación, control y gestión de los recursos hídricos, en las políticas de descentralización, ordenamiento territorial y desarrollo sustentable. La ley regula la existencia de Comisiones de Cuencas con el cometido de efectuar la gestión local de los recursos naturales (Art. 29). Introduce la dimensión ambiental que se orientan a preservar la calidad del agua y evitar que su uso no produzca efectos nocivos que puedan alterar el equilibrio ecológico y dañar el ambiente natural. La Ley 15.695 de 1984 protege especialmente al monte nativo prohibiendo su tala, mientras que Ley № 16.736 prohíbe la caza, tenencia, transporte, comercialización e industrialización de cualquier especie silvestre salvo autorización con previo informe técnico de la autoridad competente; y establece que la introducción al país de especies exóticas deberá ser previamente autorizada por el estado (Ministerio de Ganadería Agricultura y Pesca-MGAP).

Con respecto a áreas y biodiversidad objeto de protección, la Ley 13.776/69 aprueba la Convención para la Protección de la Flora, de la Fauna y de las Bellezas Escénicas Naturales de los Países de América y la Ley 16.062 aprueba la adhesión del Uruguay

WPS RI-SHUR, no6, 2017, vol.2, ISSN: 2387-1768

MONOGRÁFICO SOBRE LAS ESTRATEGIAS DE DESARROLLO URBANO

SOSTENIBLE E INTEGRADO (EDUSI) 


\title{
WPSReview International on Sustainable
}

\author{
Housing and Urban Renewal (RI-SHUR)
}

a la Convención sobre la conservación de las Especies Migratorias de Animales Silvestres (Bonn- Alemania, 1979). El Decreto 238/998, adopta las medidas pertinentes para reducir la mortalidad incidental y caza ilegal de mamíferos marinos, manteniéndose en vigor la prohibición de la persecución, caza, pesca y cualquier tipo de apropiación de ejemplares de todas las especies de pinnípedos y de cetáceos, que se encuentren en islas, costas y aguas de jurisdicción nacional, así como la prohibición de todo acto de retención, agresión o molestia que conduzca a la muerte intencional de dichos mamíferos marinos, así como cualquier otra forma de cambio, destrucción, daño o contaminación de todas aquellas zonas que fueren sus áreas naturales de reproducción, de cría o de asentamiento poblacional, lo que especifica la Ley № 19128 (2013), al crear un Santuario de Ballenas y Delfines en el mar territorial uruguayo. A lo antes mencionado se debe agregar un extenso marco jurídico sectorial, que regula los recursos, agua, suelo, biodiversidad, etc., que se desarrollan en la investigación pero exceden el alcance del artículo.

Por tanto parece que al menos desde la voluntad política y legislativa el Uruguay es en tierras americanas un pionero en el desarrollo sostenible.

\section{EL URBANISMO EN ESPAÑA SU EVOLUCION HACIA LA SOSTENIBILIDAD}

Abordados ya los aspectos generales de carácter competencial en la materia que nos ocupa, deberemos antes de profundizar en precisar este concepto en un contexto en el cual diferenciemos el urbanismo de otros ámbitos como es singularmente la ordenación del territorio, circunstancia esta que nos servirá de pauta para distinguir la atribución de competencias entre unas entidades y otras en base dichos conceptos.

En ese sentido el texto refundido de la ley de suelo y rehabilitación urbana 7/2015 al establecer el marco estatal en materia de suelo y urbanismo, recoge de forma expresa esta distinción, al remitir constantemente a la legislación territorial por un lado y a la legislación urbanística por otro, diferenciándose por tanto entre el concepto de lo urbanístico y lo territorial.

Esta diferenciación sin perjuicio de una mayor profundización en la materia, la podemos encontrar en su origen en la ley 19/1975 de reforma del régimen del suelo y ordenación urbana, que dio como consecuencia a la promulgación del texto refundido de la ley sobre el régimen del suelo y ordenación urbana, aprobado por Real Decreto Legislativo 1346/1976 de 9 de abril. En dicha norma se incorporaron los denominados planes directores territoriales de coordinación, configurando un planeamiento territorial

WPS RI-SHUR, no6, 2017, vol.2, ISSN: 2387-1768

MONOGRÁFICO SOBRE LAS ESTRATEGIAS DE DESARROLLO URBANO

SOSTENIBLE E INTEGRADO (EDUSI) 


\section{WPSReview International on Sustainable \\ Housing and Urban Renewal (RI-SHUR)}

por debajo del nonato plan nacional y por encima de los planeamientos generales, ya fueran municipales 0 los planeamiento generales de conjunto de carácter supramunicipal, pero ambos de carácter urbanístico.

Estas figuras de planificación territorial en virtud de la expresa distinción que realiza la propia Constitución en la competencia recogida en el art 148.1.3 entre urbanismo y ordenación del territorio, han sido igualmente asumidas por las Comunidades Autónomas conforme a la habilitación de dicho precepto constitucional por todos y cada uno de los Estatutos de Autonomía ya desde su primera redacción, incorporándose como competencia exclusiva de las diferentes CCAA.

Ahora bien, estas figuras de planificación territorial suponen en principio la ordenación de todos los elementos que incorporan por su propia naturaleza aspectos de carácter supramunicipal, no sólo porque afecten a diversos términos municipales, sino por el verdadero interés general alejado del interés local que tienen con incidencia en relación con las infraestructuras y servicios generales, los equipamientos aeroportuarios, ferroviarios, vías de comunicación, la ubicación de los abastecimientos de aguas y energía y sus líneas de transporte, la incidencia general sobre el medio ambiente, de los correspondientes crecimientos y su planificación general en un marco conjunto.

Dichas planificaciones territoriales no han sido objeto de un desarrollo tan pormenorizado y específico, por ser simplemente suaves en relación con la capacidad atribuida con carácter general para prácticamente todas las Comunidades Autónomas desde 1983 y ya con carácter previo todas las Comunidades Autónomas que accedieron a la autonomía con anterioridad a dicha fecha.

En ese sentido debemos destacar que son escasas las leyes de ordenación territorial y mucho más escasas las figuras de planificación territorial aprobadas al amparo de dichas leyes de ordenación territorial.

En primer lugar debemos destacar la importancia en sí misma de la ordenación territorial tal y como en su momento ya destacara LÓPEZ RAMÓN ${ }^{9}$, en tanto en cuanto esta supone una adecuada consignación de los recursos naturales de las demandas sociales y de las administraciones, así como de carácter productivo y económico interrelacionando unas y otras y estableciendo una auténtica planificación en el sentido original de la técnica de planificación en su momento reafirmada por MARTíN

${ }^{9}$ LÓPEZ RAMÓN Fernando “Estudios jurídicos sobre ordenación del territorio” Aranzadi 1995.

WPS RI-SHUR, no6, 2017, vol.2, ISSN: 2387-1768

MONOGRÁFICO SOBRE LAS ESTRATEGIAS DE DESARROLLO URBANO

SOSTENIBLE E INTEGRADO (EDUSI) 


\title{
WPSReview International on Sustainable
}

\author{
Housing and Urban Renewal (RI-SHUR)
}

RETORTILLO ${ }^{10}$, esto es la ordenación, sistematización y previsión de multitud de elementos a los efectos de la consecución de objetivos genéricos y específicos en unos plazos determinados.

En sí misma, la ordenación territorial aunque sólo fuera como instrumento de coordinación de las actuaciones de las diversas administraciones públicas con competencias sectoriales que inciden sobre el territorio, materia de infraestructuras, medio ambiente, abastecimiento de agua a poblaciones, de suministro energético y de comunicaciones, etc., tiene en sí mismo una verdadera significación y un loable y encomiable fin.

Ahora bien una verdadera planificación territorial, pese a la evidente competencia exclusiva de que gozan las Comunidades Autónomas en la materia, debe ser objeto de un necesario consenso y ponderación dada la pluralidad de intereses afectados y de competencias concurrentes en la materia por parte de la administración general del Estado, de las Entidades locales supramunicipales y de los ayuntamientos.

En segundo lugar debemos destacar que la ordenación territorial no sólo tiene como fin el anteriormente anunciado aspecto, puesto que su incidencia directa en virtud del principio de vinculación del planeamiento territorial sobre el planeamiento urbanístico general, tiene un carácter esencial de elemento de seguridad jurídica, principio consagrado por el art. 9.3 de la Constitución Española de 1978 y que supone el marco a considerar y cumplimentar por parte de las ordenaciones y planeamientos urbanísticos sobre su extensión y límites desde un punto de vista de concreción material al margen de las determinaciones legales genéricas reguladas por las leyes urbanísticas y sectoriales de la ordenación territorial aplicables a cada supuesto.

Así en los casos de existencia de una planificación territorial debidamente aprobada, dado el carácter vinculante de esta hacia los planeamientos generales, existirá un marco evidente de objetividad en relación con el ejercicio de la facultad de aprobación definitiva por parte de las Comunidades Autónomas sobre los planeamiento generales y en su caso parciales de desarrollo, que se sometan a la aprobación definitiva del órgano autonómico correspondiente para garantizar la objetividad y neutralidad de la decisión administrativa correspondiente. Puesto que el ejercicio de dichas competencias autonómicas estará limitado por el carácter reglado de la norma establecida por el planeamiento territorial correspondiente, eliminándose márgenes de discrecionalidad que normalmente incurren en la arbitrariedad derivada de cuestiones políticas, económicas, de competencia administrativa subjetiva, etc.

${ }^{10}$ MARTíN -RETORTILLO BAQUER Sebastián “derecho administrativo económico" La ley 1988. Tomo I

WPS RI-SHUR, no6, 2017, vol.2, ISSN: 2387-1768

MONOGRÁFICO SOBRE LAS ESTRATEGIAS DE DESARROLLO URBANO

SOSTENIBLE E INTEGRADO (EDUSI) 


\title{
WPSReview International on Sustainable
}

\author{
Housing and Urban Renewal (RI-SHUR)
}

Ahora bien la ausencia de una planificación territorial adecuada da lugar a la sublimación de las capacidades autonómicas para controlar el urbanismo municipal en base no a criterios objetivos y previamente determinados en una norma, sino al menos en un carácter subjetivo de la interpretación de estas y en buena parte de las ocasiones de un carácter meramente político de consagración de la supremacía del órgano autonómico sobre el municipal, en su conocimiento y decisión final sobre el territorio concreto.

Dicha habilitación genérica, que sí pudiera ser perfectamente entendible e incluso loable desde un punto de vista de la ejecución de políticas públicas específicas, no debe desprenderse del contexto de luchas de poderes que el urbanismo genera y por tanto se convierte en un claro instrumento para condicionar el modelo que pretenda adoptar un municipio de su ordenación territorial. Modelo que corresponde en cuanto a la ordenación territorial, a un marco general autonómico, pero que entra en contradicción con la concreción de políticas urbanísticas que hacen posible los planeamientos generales. Estableciéndose por tanto un ámbito subjetivo importante para la determinación de ese modelo para la Comunidad Autónoma mediante el referido informe de impacto territorial.

Por tanto una ordenación territorial previa es una materia de especial sensibilidad, en nuestra opinión, a la hora de configurar un modelo $u$ otro de ubicación de las competencias urbanísticas, puesto que la extensión y control de dicha capacidad de ordenación territorial en manos de las Comunidades Autónomas, supondrá necesariamente la adopción de un modelo u otro por vía indirecta en la detentación de competencias urbanísticas, puesto que no sólo nos encontramos ante un juego nominativo de dónde se ubican las competencias, sino qué intensidad tienen estas a la hora de su desarrollo. Dado que en caso contrario; esto es vaciamiento de la capacidad de ordenación por la vía de la determinación casuística de lo que es o no ordenación territorial, da lugar a una competencia vacua que es igual por quien se ejerza en este caso no sólo por las entidades locales municipales, sino incluso podría ejercerse en dicho aspecto, por entidades locales de ámbito inframunicipal o menor.

Partiendo de una ordenación territorial existente y por tanto vinculante hacia el urbanismo por el carácter de planificación en cascada que tiene todo el conjunto de la ordenación sobre el territorio, ya sea territorial y en su caso urbanística, debemos tener en cuenta que el urbanismo no sólo corresponde a la figura comentada de la planificación, en este caso de la planificación general como instrumento de ordenación integral de un término municipal, sino también implica la ejecución o cumplimentación

WPS RI-SHUR, no6, 2017, vol.2, ISSN: 2387-1768

MONOGRÁFICO SOBRE LAS ESTRATEGIAS DE DESARROLLO URBANO

SOSTENIBLE E INTEGRADO (EDUSI) 


\title{
WPSReview International on Sustainable
}

\author{
Housing and Urban Renewal (RI-SHUR)
}

de dicha planificación a través de la gestión urbanística y el control de la intervención sobre el uso del suelo y la edificación, y la conservación de las edificaciones, mediante las técnicas de disciplina urbanística.

Ahora bien, en el conjunto de la extensión de las competencias urbanísticas, no debemos olvidar que conforme al principio de legalidad que orienta toda la actuación de las administraciones públicas en virtud de las determinaciones constitucionales recogidas en los arts. 9‥ y $103.1^{\circ}$ de la Carta Magna, tiene especial importancia la figura de la planificación como norma jurídica de concreción de la ordenación urbanística, tanto en desarrollo de los preceptos legales conferidos a la potestad legislativa, en este caso autonómica, como por la vinculación de las determinaciones territoriales sobre el desarrollo y regulación de los modelos urbanísticos concretos que pretendan realizar las entidades administrativas competentes desde los puntos de partida de dichas ordenaciones territoriales marco.

Así por tanto, una competencia sobre planificación en esta materia urbanística es normalmente la única que es objeto de cuestionamiento sobre la ubicación de esta en una u otra entidad administrativa, puesto que las competencias de gestión y en su caso de disciplina urbanística, son sólo cuestionadas parcialmente y en relación con posibilidades subrogatorias 0 de intervención subsidiaria de las administraciones autonómicas sobre las administraciones municipales.

Junto a las tradicionales funciones del planeamiento, gestión y disciplina urbanística, no debemos olvidar que la existencia de un Estado social, conforme a las determinaciones del art. $1^{\circ}$ de nuestra Carta Magna, supone la intervención de las administraciones en la actividad económica de los particulares y su incidencia en el territorio, generándose unas capacidades de regulación e intervención que contemplan valores diferentes a los verificados mediante la clásica licencia municipal.

En ese sentido las diversas Comunidades Autónomas han regulado la materia de ordenación territorial optando, o bien por integrarlo en una regulación integral junto con el urbanismo mediante una ley única, o bien mediante leyes singulares o específicas, opción esta última mayoritaria, lo cual ha dado lugar a figuras de ordenación territorial como los Planes Regionales de Estrategia Territorial (figura prevista como ya hemos señalado por la ley 9/1995 de 28 de marzo, de medidas en materia de política territorial, suelo y urbanismo de la Comunidad de Madrid), los planes territoriales comarcales de la Comunidad Autónoma Catalana, o el Plan territorial andaluz aprobado en el año2008.

WPS RI-SHUR, no6, 2017, vol.2, ISSN: 2387-1768

MONOGRÁFICO SOBRE LAS ESTRATEGIAS DE DESARROLLO URBANO

SOSTENIBLE E INTEGRADO (EDUSI) 


\title{
WPSReview International on Sustainable
}

\author{
Housing and Urban Renewal (RI-SHUR)
}

Todas y cada una de estas figuras de planificación territorial son muy escasas en cuanto a su ordenación general y su publicación, no tanto por su laboriosidad y prolijidad en extensión, lo que implica ingentes esfuerzos y largo tiempo, sino más bien por la necesidad de que tengan elementos de seguridad jurídica para establecer un ámbito de distinción entre lo que es el urbanismo como competencia municipal y la ordenación territorial como competencia autonómica, que supone la existencia de un ámbito autonómico específico de función. Por lo tanto, pudiéndose reconducir las aprobaciones definitivas de los planeamientos generales que se atribuyen por el carácter bifásico del planeamiento urbanístico, a la entidad autonómica, un aspecto de seguridad jurídica que evitaría discrecionalidades y arbitrariedades ingentes, en su momento analizadas por DELGADO BARRIO ${ }^{11}$.

Así en estos casos, el urbanismo y sus plasmaciones en el planeamiento se supeditará, en virtud de una vinculación estricta a la previa ordenación territorial y supondrá el desarrollo de las previsiones de esa ordenación territorial y de la legislación sectorial aplicable, así como la legislación urbanística, en un espacio concreto de un término municipal, o de varios si se sigue la técnica del texto refundido de la Ley del suelo de 1976 de los planes de conjunto, circunstancia hoy difícilmente viable por la propia autonomía municipal, vinculada a una exclusividad de cada municipio.

En ese sentido debemos destacar que por su parte el municipio en sus capacidades y competencias, deberá fundamentalmente formular las figuras de planificación general y por supuesto tutelar o ejercer la gestión y ejecución del indicado planeamiento, así como la intervención sobre el uso del suelo y la edificación y la disciplina urbanística, en relación con las previas determinaciones urbanísticas.

En todo caso, se establece una concurrencia en la competencia del planeamiento urbanístico, puesto que todas las legislaciones urbanísticas, siguiendo el modelo supletorio estatal, establecen la aprobación definitiva del planeamiento general por parte de la Comunidad Autónoma, variándose en la más reciente legislación urbanística la ya asentada jurisprudencia del Tribunal Supremo en su doctrina de que dicho control sólo podría operar en las cuestiones de supramunicipalidad y de control de legalidad. Modificándose esta situación que había sido precisada de forma específica, por ejemplo en la anteriormente referida ley 9/1995 de 28 de marzo de medidas de política territorial del suelo y urbanismo de la Comunidad de Madrid, por un control mucho más difuso y amplio que pueda redundar en la discrecionalidad y a veces incluso en la arbitrariedad, en las determinaciones y de las legislaciones

${ }^{11}$ DELGADO BARRIO Javier. "El control de discrecionalidad del planeamiento urbanístico". Civitas 1993.

WPS RI-SHUR, no6, 2017, vol.2, ISSN: 2387-1768

MONOGRÁFICO SOBRE LAS ESTRATEGIAS DE DESARROLLO URBANO

SOSTENIBLE E INTEGRADO (EDUSI) 


\title{
WPSReview International on Sustainable
}

\author{
Housing and Urban Renewal (RI-SHUR)
}

autonómicas que posibilitan la revisión del planeamiento general en todos sus aspectos, a los efectos del control por las correspondientes entidades autonómica.

Tras la catarsis que supuso la Sentencia del Tribunal Constitucional 61/1997, de 20 de marzo, sobre el conjunto del derecho urbanístico estatal, circunstancia ésta especialmente ratificada por la STC 164/2001 y asumida por el propio legislador estatal en la Ley 8/2007, de 28 de mayo, de Suelo, nos encontramos con que a excepción de algún precepto con incidencia más bien "orientativa" sobre la equidistribución de beneficios y cargas de la ordenación territorial y urbanística a que hace referencia el propio texto refundido de la ley de suelo 2/2008 de 20 de junio, el conjunto del derecho urbanístico y específicamente la gestión urbanística como técnica urbanística corresponde con carácter exclusivo y excluyente a la legislación autonómica. No siendo por tanto aplicables las disposiciones estatales en esta materia más que con carácter supletorio en defecto de ley autonómica y tan sólo de forma directa a las ciudades autónomas de Ceuta y Melilla, por carecer las Asambleas de estas ciudades de potestad legislativa.

Así por el término gestión urbanística se viene entendiendo tradicionalmente el conjunto de técnicas, tanto jurídicas, como propiamente constructivas para la puesta en realidad de las determinaciones fijadas por el planeamiento, esto es la ejecución del planeamiento.

El concepto gestión tiene principalmente su origen en el Reglamento de Gestión Urbanística, aprobado por Real Decreto 3288/1978, de 25 de agosto, en el cual se regulaban ese conjunto de procedimientos, que están fundamentalmente vinculados a los procedimientos de equidistribución de beneficios y cargas que genera el planeamiento en los casos de mantenimiento de los derechos de propiedad, o a la mera tramitación de la sucesión de parcelas existentes anteriores por unas parcelas reales novedosas por su creación en base al planeamiento, en el supuesto de actuación por sistema público, singularmente el de expropiación.

Así la gestión tiene una connotación especialmente jurídica, aunque como habíamos dicho, la ejecución del planeamiento en su conjunto requiere también de un acompañamiento de medidas técnicas condicionadas fundamentalmente en torno al proyecto de urbanización y a la ejecución material de dichas obras, esto es la transformación de los terrenos mediante la implantación de los servicios que convierten el suelo en situación rural en un suelo ya urbanizado, en la terminología del texto refundido 2/2008 de 20 de junio, de la ley del suelo estatal.

WPS RI-SHUR, no6, 2017, vol.2, ISSN: 2387-1768

MONOGRÁFICO SOBRE LAS ESTRATEGIAS DE DESARROLLO URBANO

SOSTENIBLE E INTEGRADO (EDUSI) 


\title{
WPSReview International on Sustainable
}

\author{
Housing and Urban Renewal (RI-SHUR)
}

Desde que el Tribunal Constitucional en las ya referidas sentencias 61/1997 y 164/2001, consagró la definitiva capacidad exclusiva de las Comunidades Autónomas en relación con la regulación del urbanismo, se ha producido un claro fenómeno en cuanto a la autonomización del derecho urbanístico ${ }^{12}$ y en ese sentido debemos destacar que los tres grandes ámbitos clásicos de la legislación urbanística (siguiendo los reglamentos ejecutivos del texto refundido de la Ley del Suelo de 1976), esto es el planeamiento, la gestión y la disciplina urbanística, han sido asumidos en las legislaciones por las Comunidades Autónomas con un carácter exclusivo, quedando desplazadas las disposiciones estatales existentes en la materia, a mero derecho supletorio.

En cuanto al régimen de la intervención urbana en el derecho estatal, lo podemos estructurar, tal y como afirma SÁNCHEZ GOYANES ${ }^{13}$, como tres círculos concéntricos. Siendo el primero el de la ciudadanía en general que son derechos de orden socioeconómico y medioambiental, independientemente de su relación subjetiva de propiedad u otro aspecto con respecto al suelo, así como su derecho para la creación de acceso igualitario de las dotaciones de servicios y espacios colectivos que en opinión del legislador demandan la calidad y cohesión del mismo.

Un segundo círculo concéntrico es la configuración de la actividad urbanística como una actividad económica de interés general, que afecta tanto al derecho de propiedad recogido en el Art. 33 de la Constitución, como al derecho de libertad de empresa contemplado en el Art. 38 de la ley de leyes.

Pues bien, ese segundo círculo concéntrico nuclear, que GOYANES define como complementario y adicional, implica un título habilitante para la ejecución material y jurídica del planeamiento, que obviamente en la configuración de la ley, tiene un carácter más extenso que el propio derecho de propiedad, en tanto en cuanto la iniciativa privada en la urbanización, construcción y edificación previsto por el art. 6으 del Texto Refundido de la ley de Suelo 2/2008, supone un derecho no sólo para el propietario concretado en el apartado d), derecho de construcción, sino un derecho de iniciativa de los particulares, sean o no titulares de los terrenos, en ejercicio de la libre empresa para actividades de ejecución de la urbanización, cuando esta no debe o vaya a realizarse por la propia administración competente.

\footnotetext{
${ }^{12}$ PARADA Ramón lo describe como "jibarización" al respecto vid "Ramón Parada Vázquez "Derecho Urbanístico". Marcial Pons. 2008

${ }^{13}$ SÁNCHEZ GOYANES Enrique. "El derecho estatal del suelo tras la refundición de 2008" Pags. 5 a 58 de Especial texto refundido de la ley del suelo. La Ley. 2008
}

WPS RI-SHUR, no6, 2017, vol.2, ISSN: 2387-1768

MONOGRÁFICO SOBRE LAS ESTRATEGIAS DE DESARROLLO URBANO

SOSTENIBLE E INTEGRADO (EDUSI) 


\title{
WPSReview International on Sustainable
}

\author{
Housing and Urban Renewal (RI-SHUR)
}

En ese margen, el régimen general estatal, establece una expresa habilitación y para la introducción de un principio de concurrencia empresarial en la ejecución del planeamiento, privando del derecho directo a urbanizar a los propietarios, siempre en defecto de la actuación administrativa que comprende el ejercicio de la función pública urbanística.

Finalmente nos encontramos, siguiendo lo que Sánchez Goyanes ha señalado como círculos concéntricos, el tercer círculo a los anteriores que es el estatuto propio del ciudadano que ostenta el título de propiedad del suelo, que continua en el régimen jurídico estatal del Texto Refundido del 2008(y ahora del 2015), con la línea clásica sobre la concepción estatutaria del derecho de propiedad.

Ahora bien, limitando el derecho de propiedad con respecto a normativas anteriores, puesto que como ya hemos indicado anteriormente se le priva de un derecho a urbanizar que queda en manos de la administración, siendo el propietario simplemente un agente de la administración en cuanto urbanice, sea él directamente, sea a través de las figuras anteriormente relatadas previstas por las diversas legislaciones autonómicas que podemos unificar simplificadamente bajo el término de "agente urbanizador".

Partiendo de esos tres círculos concéntricos, la regulación estatal del TRLS 7/2015, mantienen la absoluta competencia autonómica en relación con el proceso urbanístico, incluso en la clasificación del suelo, por tanto en mayor medida con respecto a la determinación de las concretas fórmulas de gestión urbanística.

Ahora bien, sí se establecen una serie de principios y directrices generales en relación con la gestión, como la ya indicada de la privación del derecho subjetivo de urbanizar de los propietarios y su configuración como una capacidad de promoción de la urbanización, tanto para los particulares propietarios, como para otros particulares, siempre y cuando la administración no decida ejercer dicha facultad de forma directa, esto es, dejando al libre albedrío de la administración, la determinación de lo que hoy conocemos como sistemas de ejecución, ya sea la expropiación como forma característica de gestión directa, u otras fórmulas, configuradas todas ellas por la legislación urbanística.

Debemos por tanto partiendo de la realidad actual observar el futuro inmediato de la ordenación urbana, que en nuestra opinión y tras la etapa desarrollista del urbanismo, que tan acertadamente denunciara MARTIN MATEO ${ }^{14}$, se centra cada vez más en los

${ }^{14}$ MARTIN MATEO, Ramón "La gallina de los huevos de cemento " Civitas , 2007

WPS RI-SHUR, no6, 2017, vol.2, ISSN: 2387-1768

MONOGRÁFICO SOBRE LAS ESTRATEGIAS DE DESARROLLO URBANO

SOSTENIBLE E INTEGRADO (EDUSI) 


\section{WPSReview International on Sustainable \\ Housing and Urban Renewal (RI-SHUR)}

modelos de sostenibilidad que preconizan una ciudad compacta, eso si modelo no exento de críticas, tal y como demuestra AMENOS ${ }^{15}$.

Esa nueva perspectiva de la ordenación urbana caracterizada por la sostenibilidad económica, social y ambiental tiene su plasmación concreta en los dos fenómenos que se han pretendido analizar en el trabajo que ahora se publica la rehabilitación y las técnicas que se incorporan al fenómeno de smart cities.

Esta materia de la ordenación urbana, es salvo algunas cuestiones vinculadas a competencias concurrentes sobre la misma una competencia que el ordenamiento jurídico español atribuye a las Comunidades autónomas y por tanto además de la diversidad de origen geográfico de los ponentes (Andalucía, Asturias, Cataluña, Castilla-La Mancha y, Canarias) contó con un referente madrileño en la figura del proyecto de nueva Ley del Suelo de dicha Comunidad.

En esa línea el nuevo prisma de ordenación urbana y su imprescindible sostenibilidad tanto económica ${ }^{16}$, como social (materia ya analizada en otros trabajos por el profesor Juli PONCE) y ambiental exigen contar con todos los medios que las tecnologías actuales permiten para disminuir el impacto que el desarrollo urbano tiene en nuestro entorno.

Estos medios están necesariamente unidos al municipio como espacio de convivencia y entidad administrativa detentadora.

En cualquier caso lo nuevo debe de partir de la existencia de unos fundamentos tradicionales del urbanismo, esto es la regulación del entorno urbano, que se adaptan a las nuevas necesidades y recursos tecnológicos.

Este bagaje tradicional del urbanismo, como ciencia pluridisciplinar, no impide que se incorporen nuevas tecnologías y desde luego las tecnologías de la información y la comunicación a su análisis, gestión y desarrollo, tal y como ya en su día describimos y como para el supuesto de nuestros días se pretende destacar en esta obra.

\footnotetext{
${ }^{15}$ AMENÓS ÁLAMO, Joan El mito legal de la ciudad compacta, Universitat Autònoma de Barcelona, Barcelona, 2015,

${ }^{16} \mathrm{Al}$ respecto vid ALONSO IBAÑEZ Rosario "La viabilidad económica de los procesos de regeneración urbana".Págs 05 a 110 , de la obra colectiva "Las nuevas perspectivas de la ordenación urbanística y del paisaje: smart cities y rehabilitación. Una perspectiva hispano-italiana GARCIA RUBIO, Fernando (Director), fundación Democracia y gobierno local, 2017.
}

WPS RI-SHUR, no6, 2017, vol.2, ISSN: 2387-1768

MONOGRÁFICO SOBRE LAS ESTRATEGIAS DE DESARROLLO URBANO

SOSTENIBLE E INTEGRADO (EDUSI) 


\title{
WPSReview International on Sustainable
}

\author{
Housing and Urban Renewal (RI-SHUR)
}

De hecho no se puede entender el urbanismo de nuestros días sin los sistemas de información y análisis geográfico no solo para el diagnóstico, sino también para formar parte de la propia documentación que configura el planeamiento urbanístico.

Pero debemos recordar que la moderna ordenación urbana no solo es el planeamiento tradicional en sus tres vertientes (territorial, general y de desarrollo), sino que debe contemplar toda una serie de estudios y requisitos de carácter sectorial que permitan la sostenibilidad de nuestro modelo de convivencia ciudadana.

En esencia, lo limitado de los recursos territoriales como el suelo y el agua requiere que la ordenación de las relaciones humanas con su entorno ambiental, bajo un prisma de sostenibilidad, lo que exige que las poblaciones existentes se ordenen de forma inteligente y preservando y recuperando las edificaciones y actuaciones ya realizadas.

Pero partiendo de esos fundamentos tradicionales si debe reconocerse que tras la Ley de suelo 8/2007 y especialmente con la denominada Ley de las tres erres (Ley 8/2013, de 26 de junio, de rehabilitación, regeneración y renovación urbanas), sin olvidar el periodo intermedio ${ }^{1718}$, se ha producido una nueva perspectiva del urbanismo, que junto al necesario endurecimiento de las normas y procedimientos ambientales y la gravísima crisis económica del sector inmobiliario en el periodo 2007-2015, ha propiciado un innegable desarrollo de las técnicas rehabilitadoras.

Esas funciones y técnicas rehabilitadores son de carácter urbanístico, máxime tras la integración de la Ley 8/2013, de 26 de junio, de rehabilitación, regeneración y renovación urbanas), en la legislación urbanística estatal con el vigente Texto refundido de la Ley de suelo, esto es el Real Decreto Legislativo 7/2015, de 30 de octubre, por el que se aprueba el texto refundido de la Ley de Suelo y Rehabilitación Urbana.

Pero la perspectiva de conservación y lo que GONZALEZ-VARAS IBAÑEZ ${ }^{19}$ denominó estado de la cultura, no es por si solo el fundamento de la rehabilitación urbana, puesto que esta no solo supone conservar las edificaciones preexistentes, sino

\footnotetext{
${ }^{17}$ Sobre esto vid BASSOLS COMA, Martín "Genesis y evolución del derecho urbanístico español ", Montecorvo

${ }^{18} \mathrm{Al}$ respecto ALONSO IBAÑEZ, Rosario "La intervención en la ciudad existente: las actuaciones de rehabilitación en las reformas legislativas del periodo 2010-2011", en Ciudad y Territorio. Estudios Territoriales, 174, 2012, pp. 639-654.

${ }^{19}$ GONZALEZ-VARAS IBAÑEZ, Santiago "La rehabilitación urbanística "Aranzadi , 1998, pags 33 y ss
}

WPS RI-SHUR, no6, 2017, vol.2, ISSN: 2387-1768

MONOGRÁFICO SOBRE LAS ESTRATEGIAS DE DESARROLLO URBANO

SOSTENIBLE E INTEGRADO (EDUSI) 


\title{
WPSReview International on Sustainable
}

\author{
Housing and Urban Renewal (RI-SHUR)
}

mejorarlas, regenerarlas, cambiarlas de uso, mejorando problemas de movilidad limitaciones "gentrificadoras", posibilitando una mejor y más viable convivencia urbana.

Así, parece evidente que la rehabilitación no es una mera restauración, materia ya muy desarrollada en Italia ${ }^{20}$, tal y como el estudio del profesor Tanda $^{21}$ en esta obra se encarga de resaltar, sino que supone un avance y generalización de una técnica que se había limitado a las edificaciones de valor histórico, ya desde la Instrucción de 1802, tal y como constato FERNANDEZ RODRIGUEZ ${ }^{22}$.

De hecho la rehabilitación ha sido ya abordada de manera exhaustiva por nuestra doctrina administrativa de forma muy exhaustiva y desde ya antiguo, por autores como LOPEZ RAMON ${ }^{23}$ y QUINTANANA LOPEZ ${ }^{24}$, pero todos ellos y el concepto mismo, suponen, como ya explicara PORTO REY ${ }^{25}$, el paso de una perspectiva de mera conservación e incluso adaptación a nuevos tiempos y realidades de meros inmuebles aislados a una revisión integrada en el planeamiento urbano.

De hecho, tal y constata GONZÁLEZ-VARAS ${ }^{26}$ rehabilitar supone superar la concepción de la mera conservación vinculada a los centros históricos equiparándose para todo el territorio de la ciudad con la sustitución, el saneamiento y la modernización, nivelándose en los términos de SERRANO GUIRAO ${ }^{27}$ a la renovación, puesto que comprende, tal y como hemos apuntado no solo las edificaciones (y no tan solo los edificios, sino también estatuas, mobiliario urbano, fuentes, etc.), sino el espacio mismo.

Pueden dentro de ese ámbito de la renovación producirse actuaciones que la rehabilitación implique conservación con meras sustituciones parciales, o por otro lado

\footnotetext{
${ }^{20}$ Así SPERONI, M, La tutela dei beni culturali negli stati italiani preunitari.L'Etá delle riforme l" Giuffré . Milan 1988 y

${ }_{21}$ TANDA Paolo "Realización de reestructuración de edificios y remodelación urbana en Italia tras el Decreto legislativo 222/2016" pags 45 a 58 de GARCIA RUBIO, Fernando (coordinador)"Las nuevas perspectivas de la ordenación urbanística y del paisaje ;smart cities y rehabilitación .Una perspectiva hispano -italiana", Fundación Democracia y gobierno local , 2017.

22 FERNANDEZ RODRIGUEZ, Tomas Ramón "La legislación española sobre Patrimonio históricoartístico. Balance de la situación de cara al futuro "Revista de derecho urbanístico (1978) n69

${ }_{23}^{2}$ LÓPEZ RAMÓN Fernando Perspectivas jurídicas de la rehabilitación urbana

Revista española de derecho administrativo,, № 43, 1984, págs. 535-562

${ }^{24}$ QUINTANANA LOPEZ, Tomás "Régimen competencial del urbanismo, vivienda y rehabilitación urbana" REALA n² 239, 1988 pags 1471-1490.

25 PORTO REY, Enrique. De la conservación individualizada del patrimonio inmobiliario a su rehabilitación integrada en el planeamiento urbano "Revista de derecho urbanístico nº109, 1988, pags 13 y ss.

${ }^{26}$ GONZALEZ-VARAS IBAÑEZ, Santiago Op cit "La rehabilitación... pag

27 SERRANO GUIRAO, E. "La administración local y los problemas de renovación urbana" RAP n 36 , 1972 , pags 13 y siguientes.
}

WPS RI-SHUR, no6, 2017, vol.2, ISSN: 2387-1768

MONOGRÁFICO SOBRE LAS ESTRATEGIAS DE DESARROLLO URBANO

SOSTENIBLE E INTEGRADO (EDUSI) 


\section{WPSReview International on Sustainable \\ Housing and Urban Renewal (RI-SHUR)}

actuaciones rehabilitadoras que para regenerar un ámbito concreto requieran de previas demoliciones.

Estas distinciones ya fueron analizadas por la doctrina italiana desde antiguo ${ }^{28}$, pero a nuestro juicio desde una perspectiva meramente conservacionista y no rehabilitadora, aunque progresivamente y tal y como describe GONZALEZ-VARAS ${ }^{29}$, de forma superpuesta a la legislación urbanística (al menos hasta la ya indicada Ley 8/2013de 26 de junio, de rehabilitación, regeneración y renovación urbanas). Han ido ganando sustantividad propia.

Estas determinaciones sobre rehabilitación hacen que el ya clásico deber de conservación de edificaciones y urbanizaciones venga ahora complementado por el de rehabilitación, tal y como se determina en el vigente TRLSRU estatal y las diversas leyes de las CCAA, cuyo ejemplo en transformación analizado en esta obra es el de la Comunidad de Madrid, pero que los diferentes trabajos abordan desde muy diversas perspectivas autonómicas.

Pero las funciones y técnicas de regeneración de los territorios ya sometidos a actuación o explotación humana no solo se deben centras en meros aspectos de rehabilitación o recuperación de edificaciones, sino que deben tener una óptica integral del espacio, ya sea desde los aspectos(hoy claves) energéticos, pasando por la necesaria limitación y tratamiento de los residuos hasta los ámbitos sometidos a antiguas explotaciones industriales o mineras.

Esta nueva perspectiva de la regeneración y recuperación posibilita fenómenos como Tribeca en Nueva York, los Docklands Iondinenses, o Cabárceno en Cantabria.

En cualquier caso como todas las actuaciones administrativas y en especial las de ordenación urbana exigen de una valoración que tiene un imprescindible componente económico, sobre todo por la complementación del art 31 CE hace la nueva redacción desde 2011 del art 135 de la Carta Magna, lo que es destacado en este aspecto de la renovación urbana por la profesora Alonso.

En cualquier caso, y tal y como se extrae de la experiencia italiana, y de nuestro devenir histórico, es evidente que el moderno derecho urbanístico independientemente del enfoque autonómico correspondiente, debe trasladar los esfuerzos desde una

\footnotetext{
${ }^{28}$ Un panorama histórico lo encontramos en CASSESE, Sabino "I beni culturali da Bottai a Spodolini" pags 116 a 142 de Rassegna degli archivi di Stato, Roma, Enero-diciembre 1975(no 1,2 y 3 año XXXV.

${ }^{29}$ GONZALEZ-VARAS IBANEEZ, Santiago Op cit "La rehabilitación... pag 170
}

WPS RI-SHUR, no6, 2017, vol.2, ISSN: 2387-1768

MONOGRÁFICO SOBRE LAS ESTRATEGIAS DE DESARROLLO URBANO

SOSTENIBLE E INTEGRADO (EDUSI) 


\title{
WPSReview International on Sustainable
}

\author{
Housing and Urban Renewal (RI-SHUR)
}

planificación y edificación ex novo hacia una labor rehabilitadora y regeneradora de espacios ya urbanizados o explotados, como parte de la consolidación de un modelo de desarrollo urbano y humano sostenible, tal y como apunta para el caso español GIFREU ${ }^{30}$.

Pero eso reduplicará el papel de las poblaciones y sus organizaciones administrativas por excelencia, los ayuntamientos, en sentido de generar soluciones y los correspondientes recursos y servicios para destacar de forma inteligente(Smart) esa nueva perspectiva y su gestión facilitando la vida en un mismo espacio a un creciente número de seres humanos que requieren más y mejores servicios, como son los ya referidos aspectos del suministro y tratamiento de aguas, la retirada y tratamiento de residuos o la clave movilidad urbana.

Junto a esta dimensión tecnológica no debe de dejarse al margen un aspecto estético, la búsqueda de la belleza, por la que el ser humano ha realizado a lo largo de su existencia tantos esfuerzos y actuaciones, desde Altamira y Lascaux en el paleolítico, hasta la capilla Sixtina del Vaticano o los nenúfares de Monet, que se pueden contemplar en la Orangerie de París, la humanidad ha estado siempre en la búsqueda de la belleza y su consecución en el entorno que le rodea.

La convivencia en el seno de las poblaciones,tanto entre los seres humanos, como de estos con su entorno exige, dada la naturaleza del propio ser humano, una serie de reglas que establezcan una adecuada preservación de esta y del entorno inmediato en el que las poblaciones se asientan y dentro de los asentamientos su impacto visual. Dicha concepción visual del entorno, con los matices que a continuación desarrollaremos, es lo que podemos considerar como el paisaje, circunstancia sobre la que ya hemos realizado unas reflexiones generales en otros trabajos ${ }^{31}$.

\footnotetext{
${ }^{30}$ GIFREU FONT Judith" Las actuaciones sobre el medio urbano como nueva frontera de las políticas públicas al servicio de las de la sostenibilidad territorial y urbanística de la obra colectiva" pags pags 59 a 94 de "Las nuevas perspectivas de la ordenación urbanística y del paisaje :smart cities y rehabilitación. Una perspectiva hispano-italiana GARCIA RUBIO, Fernando (Director) , fundación Democracia y gobierno local , 2017.

${ }^{31}$ GARCIA RUBIO, Fernando "Régimen jurídico particular del paisaje urbano. Entre las determinaciones de adaptación al ambiente, las normas sectoriales y la regulación de la estética en el ámbito de la autonomía local". Dentro de El derecho de la ciudad y el territorio: estudios en homenaje a Manuel Ballbé Prunés / Judith Gifreu i Font (dir.), Martín Bassols Coma (dir.), Angel Menéndez Rexach (dir.), 2016, , págs. 448-473.
}

WPS RI-SHUR, no6, 2017, vol.2, ISSN: 2387-1768

MONOGRÁFICO SOBRE LAS ESTRATEGIAS DE DESARROLLO URBANO

SOSTENIBLE E INTEGRADO (EDUSI) 


\title{
WPSReview International on Sustainable
}

\author{
Housing and Urban Renewal (RI-SHUR)
}

Así son muchas las disciplinas que abordan el estudio del paisaje, tal y como especificó BLÁZQUEZ JIMÉNEZ ${ }^{32}$ (biólogos, ecólogos, arquitectos, geógrafos, sociólogos, estudiosos del arte, o incluso los autodenominados paisajistas(de hecho existe una asociación española de paisajistas), que diseñan entornos ajardinados e incluso operaciones urbanas, algo que da pie a que el término paisaje adquiera muchos matices, todos ellos con su validez mayor o menor y siempre con campos de investigación propios: paisaje visual, paisaje geográfico, paisaje ecológico, paisaje cultural, etc. El carácter interdisciplinar de este concepto tiene sus ventajas, al quedar abierto a múltiples ideas, pero a su vez existe el reconocimiento de que este hecho puede crear ciertas interferencias en su análisis e interpretación, de modo que ciertas tipologías diferentes de paisaje pueden interpretarse de distinta manera según la disciplina que lo trate.

Igualmente el paisaje implica una percepción visual de un hecho físico lo que da lugar a una mezcla de elementos subjetivos (percepción) y objetivos (el hecho físico) que genera una mezcla a veces controvertida sobre que paisajes proteger, o no.

Esta circunstancia, la percepción subjetiva de hechos implica la necesidad de abordar el parámetro de análisis de esa percepción, que es la anteriormente descrita estética.

Desde esta óptica, algunos autores consideran que el concepto de paisaje está integrado por tres elementos: el espacio físico, la referencia visual, y el factor estético. $Y$ aluden a dos realidades distintas: por un lado, el ámbito físico natural, que reúne ciertas características singularmente protegidas por su fragilidad, rareza o belleza; y, por otro, el paisaje cultural, que puede predicarse de las áreas urbanas especialmente cualificadas por la presencia de un conjunto histórico-artístico.

En estos supuestos, el paisaje preexistente es considerado un bien jurídico que debe preservarse. En suma, la concepción subjetiva del paisaje nos conduce a su construcción conceptual como expresión estética sustentada por percepciones subjetivas y de armonía estética propias de cada tiempo y lugar que se apoyan en los más variados elementos materiales e inmateriales.

Este renovado enfoque del paisaje hace que sea objeto de preservación no sólo a través de las políticas ambientales sino también de las territoriales. Y no sólo eso. Hace que la defensa del paisaje sea también una defensa de las percepciones y no sólo de los bienes que lo integran.

\footnotetext{
${ }^{32}$ BLÁZQUEZ JIMÉNEZ, Antonio “Las dimensiones del paisaje urbano” revista Práctica Urbanística 13 .1 2016 Wolters Kluwer España.
}

WPS RI-SHUR, no6, 2017, vol.2, ISSN: 2387-1768

MONOGRÁFICO SOBRE LAS ESTRATEGIAS DE DESARROLLO URBANO

SOSTENIBLE E INTEGRADO (EDUSI) 


\title{
WPSReview International on Sustainable
}

\author{
Housing and Urban Renewal (RI-SHUR)
}

En cualquier caso debe resaltarse que el paisaje, como noción, es un concepto antropocéntrico, pues presupone que alguien va a verlo o mirarlo, porque las personas van a transitar por allí para admirarlo. La protección ambiental en sí misma, el concepto centrado en la naturaleza salvaje de medio ambiente, queda al margen del paisaje, sobre todo cuando el paisaje existente no es digno de protección por sus características estéticas de paisaje

Asumiendo ya una concepción jurídico-positiva, de forma previa y con carácter general debemos entender como paisaje, tal y como se recoge en el convenio europeo del paisaje, celebrado en el Consejo de Europa y ratificado por España ${ }^{33}$, lo siguiente: "«paisaje» se entenderá cualquier parte del territorio tal como la percibe la población, cuyo carácter sea el resultado de la acción y la interacción de factores naturales y/o humanos" (como veremos literalmente tomado del convenio europeo) Este concepto es asumido, como es lógico por nuestros poderes públicos distinguiéndose normalmente a los efectos de su regulación entre paisaje natural y monumental, no existiendo una regulación general estatal sobre la materia de paisaje urbano, por lo que las normas aplicables son de materias concurrentes sobre el propio paisaje, o de carácter autonómico y local.

En ese sentido y tal y como apunta CARBALLEIRA ${ }^{34}$ el paisaje es una preocupación reciente en el Derecho español. Históricamente la mayoría de las normas sectoriales que incidían sobre el territorio, la cultura y el medio natural albergaban medidas puntuales de carácter paisajístico. Sin embargo, esto no fue sino una pequeña pincelada jurídica que en algunos casos se reveló como contraproducente al impedir dotar de sustantividad propia a la materia. La toma de conciencia internacional sobre el paisaje junto con la reciente legislación paisajística autonómica que desde la última década se promulgó en nuestro país, ayudó sobremanera a emancipar la disciplina, así como diseñar un régimen jurídico autónomo que acoge la creación de estructuras organizativas, técnicas e instrumentos dirigidos específicamente a tutelarlo.

\footnotetext{
${ }^{33}$ (BOE de 5 de febrero de 2008), al respecto vid FERNÁNDEZ RODRíGUEZ, C., "El paisaje, el medio rural y el patrimonio natural en las recientes iniciativas legislativas estatales. (A propósito de la ratificación por España de la Convención europea del Paisaje, la Ley 45/2007, de 13 de diciembre, para el desarrollo sostenible del medio rural y la Ley 42/2007, de 13 de diciembre, del Patrimonio Natural y de la Biodiversidad)", en Civitas Revista española de Derecho Administrativo núm. 140/2008 y MATA OLMO Rafael "Convenio europeo del paisajedel Consejo de Europa. Notas sobre su aplicación en España"Patrimonio cultural y derecho,, № 18, 2014, págs. 175-206

${ }^{34}$ CARBALLEIRA RIVERA Maria Teresa "El paisaje como bien cultural" dentro de la obra colectiva "EI camino de santiago y otros itinerarios Cultura, historia, patrimonio, urbanismo, turismo, ocio y medio ambiente" LIBER AMICORUM ENRIQUE GÓMEZ-REINO Y CARNOTA" Coordinadores Juan Ramón Fernández Torres Jesús Prieto de Pedro Joan Manuel Trayter Jiménez, Tirant lo Blanch, Escola Galega de administración pública , 2014
}

WPS RI-SHUR, no6, 2017, vol.2, ISSN: 2387-1768

MONOGRÁFICO SOBRE LAS ESTRATEGIAS DE DESARROLLO URBANO

SOSTENIBLE E INTEGRADO (EDUSI) 


\title{
WPSReview International on Sustainable
}

\author{
Housing and Urban Renewal (RI-SHUR)
}

Pero debemos señalar una falta de regulación específica y general estatal del paisaje, que ha sido subsanada por algunas CCAA y así como define el art 6.1 de la Ley 5/2014, de 25 de julio, de Ordenación del Territorio, Urbanismo y Paisaje, de la Comunitat Valenciana:paisaje es cualquier parte del territorio, tal y como es percibido por sus habitantes, cuyo carácter resulta de la interacción de factores naturales y humanos

Como resalta la indicada CARBALLEIRA ${ }^{35}$ El paisaje es un elemento o paraje natural mitificado. De ese modo lo recoge la primera ley italiana que lo reguló, la Ley 1497/1939(anterior a la Ley del suelo de 1942), al definirlo como expresión de una belleza natural o artificial que se goza estéticamente, inseparable de los elementos que lo conforman ${ }^{36}$. Así pues, en esta primera etapa, el paisaje en tanto que belleza natural se concibe como parte del medio ambiente, como un recurso natural que exige una utilización racional y un deber de los poderes públicos de protegerlo, para lo cual se conecta al artículo $45 \mathrm{CE}$.

Siguiendo a PEREZ GONZALEZ ${ }^{37}$ por otra parte el Derecho Urbanístico español y la propia conciencia social han ido avanzando desde una permisividad generalizada del ejercicio del Derecho a la propiedad, sin límites o limitaciones que lo acotaran a una conciencia cada vez más notable de protección del medio ambiente y singularmente del paisaje. Todo ello, en el marco del derecho a disfrutar de un medio ambiente adecuado enunciado por el art. 45 de nuestra Carta Magna, debiendo significarse la creciente interrelación entre lo ambiental y lo territorial y la necesidad de su adecuada coordinación, hasta el punto de que la reciente Ley 42/2007, de 13 de diciembre,del Patrimonio Natural y de la Biodiversidad, ha llegado a proclamar en su Exposición de Motivos «la prevalencia de la protección ambiental sobre la ordenación territorial y urbanística». Y ello a pesar de que esta transformación ha sido más dilatada en el tiempo de lo deseado y evocando al anteriormente citado Martín Mateo ${ }^{38}$, podría decirse que: «El hombre tiene aproximadamente 2 millones de años, la Era Cristiana, 2000, la Revolución Industrial, 200 y la Reacción Ambiental 20».

El concepto del Derecho del paisaje ha evolucionado hacia posiciones sociales y participativas, partiendo a principios del siglo XX de una «concepción elitista».

\footnotetext{
${ }^{35}$ CARBALLEIRA RIVERA, Maria Teresa Op cit "El paisaje como bien cultural

${ }^{36}$ Sobre esto vease CARTEI , GIANFRANCO "Autonomia locale e planificazione del paesaggio" pags 703

a 743 de Rivista trimestrale di diritto pubblico, , № 3, 2013, ed Giufré , Milan. Y en concreto pags 704-706.

${ }^{37}$ PEREZ GONZALEZ, Carlos "Relaciones entre la ordenación urbanística y la protección del paisaje"El Consultor de los Ayuntamientos, № 13, Sección Colaboraciones, Quincena del 15 al 29 Jul. 2008, Ref. 2322/2008, pág. 2322, tomo 2, Editorial LA LEY

${ }^{38}$ MARTIN MATEO, Ramón "Manual de derecho ambiental “ Aranzadi , 2005.
}

WPS RI-SHUR, no6, 2017, vol.2, ISSN: 2387-1768

MONOGRÁFICO SOBRE LAS ESTRATEGIAS DE DESARROLLO URBANO

SOSTENIBLE E INTEGRADO (EDUSI) 


\section{WPSReview International on Sustainable \\ Housing and Urban Renewal (RI-SHUR)}

En el marco de las actuaciones públicas encaminadas a la protección y mejora de la calidad de vida se encuentra de forma singular la protección y mejora del paisaje como «un elemento esencial para el bienestar individual y social, cuya protección, gestión y planeamiento comportan derechos y deberes para todos", en la definición utilizada por el Convenio europeo del paisaje, aprobado por el Consejo de Europa el día 20 de octubre de 2000 en Florencia, que ha entrado en vigor en nuestro país el 1 de marzo de 2008.

Esa concepción del paisaje que ha sido de forma tradicional vinculada a las zonas rurales y a la protección de cascos históricos debe bajo la nueva perspectiva anteriormente explicada de una ciudad compacta, mas habitable, disfrutable e inteligente.

Cabe por tanto a la vista de los conceptos anteriormente apunados y destacando los paralelismos e influencias del derecho italiano sobre el español, la necesidad de resaltar, tal y como se ocupan de abordar los trabajos incluidos en este volumen, la importancia clave del uso de técnicas y actuaciones rehabilitadoras e "inteligentes" para poder desarrollar una ordenación urbana "inteligente" que posibilite una concepción del urbanismo actual y de futuro bajo un nuevo prisma, que pondere la disminución del consumo energético, la disminución y valoración de la emisión de residuos y gases contaminantes, el uso más racional y eficiente del agua y la racionalización del uso de los vehículos limitando el uso de los de carácter privado y en especial los propulsados mediante combustibles fósiles.

Todo ello posibilitará la recuperación de espacios ya vividos, pero no necesariamente perdidos, regenerando los paisajes urbanos existentes.

\section{METODOLOGÍA}

Para el desarrollo del presente trabajo se ha seguido el sistema de una previa visita in situ de los cuatro países con análisis de la bibliografía científica, búsqueda en webs oficiales y tras la lectura y examen de estas fuentes se ha procedido a la elaboración de un texto en la línea clásica del derecho comparado.

\section{RESULTADOS Y CONCLUSIONES}

Conforme todo lo anteriormente expuesto, podemos destacar que pese a la diversidad geográfica todos los países y sus ordenamientos plasman si no de forma expresa si en

WPS RI-SHUR, no6, 2017, vol.2, ISSN: 2387-1768

MONOGRÁFICO SOBRE LAS ESTRATEGIAS DE DESARROLLO URBANO

SOSTENIBLE E INTEGRADO (EDUSI) 


\title{
WPSReview International on Sustainable
}

\author{
Housing and Urban Renewal (RI-SHUR)
}

cuanto lo que podríamos denominar "filosofía" el principio del desarrollo sostenible, incluso con un nivel de reconocimiento constitucional, pero expresamente vinculado al medio ambiente y olvidando, en dichos preceptos constitucionales los otros dos ejes de la sostenibilidad(el social y el económico).

Ahora bien esta plasmación constitucional requiere de un adecuado desarrollo legislativo no realizado (por ejemplo la República Dominicana carece de ley de ordenación territorial) y especialmente de un cambio real en las prácticas administrativas y ciudadanas.

Desde luego los objetivos del desarrollo sostenible no han sido implementados en ningún país en la versión de la agenda urbana de la II cimbre de ONU Habitat celebrada en Quito en 2017, pero aún hay tiempo si hay voluntad.

\section{REFERENCIAS BIBLIOGRÁFICAS}

ALONSO IBAÑEZ, Rosario "La intervención en la ciudad existente: las actuaciones de rehabilitación en las reformas legislativas del periodo 2010-2011", en Ciudad y Territorio. Estudios Territoriales, 174, 2012, pp. 639-654.

"La viabilidad económica de los procesos de regeneración urbana", pags 05 a110, de la obra colectiva "Las nuevas perspectivas de la ordenación urbanística y del paisaje:smart cities y rehabilitación. Una perspectiva hispano-italiana GARCIA RUBIO, Fernando (Director) , fundación Democracia y gobierno local , 2017.

ÁLVAREZ LENZI, , Ricardo (1986): Fundación de poblados en Uruguay, Montevideo, Farq-UdelaR.,

BARACCHINI, H. y ALTEZOR, C. (2008): "Historia del ordenamiento territorial en el Uruguay", Montevideo, Trilce 82).

BASSOLS COMA, Martín "Genesis y evolución del derecho urbanístico español ", Montecorvo, 1974

CARBALLEIRA RIVERA, Maria Teresa "EI paisaje como bien cultural" dentro de la obra colectiva "El camino de santiago y otros itinerarios Cultura, historia, patrimonio, urbanismo, turismo, ocio y medio ambiente" LIBER AMICORUM ENRIQUE GÓMEZREINO Y CARNOTA" Coordinadores Juan Ramón Fernández Torres Jesús Prieto de

WPS RI-SHUR, no6, 2017, vol.2, ISSN: 2387-1768

MONOGRÁFICO SOBRE LAS ESTRATEGIAS DE DESARROLLO URBANO

SOSTENIBLE E INTEGRADO (EDUSI) 


\section{WPSReview International on Sustainable \\ Housing and Urban Renewal (RI-SHUR)}

Pedro Joan Manuel Trayter Jiménez, Tirant lo Blanch, Escola Galega de administración pública , 2014

CARMONA, L. y GÓMEZ, M.L. (1999): "Montevideo, proceso planificador y crecimientos", Montevideo, Farq-UdelaR. 28).

CARTEI , GIANFRANCO "Autonomia locale e planificazione del paesaggio" pags 703 a 743 de Rivista trimestrale di diritto pubblico, № 3, 2013, ed Giufré, Milan. Y en concreto pags 704-706.

DELGADO BARRIO, Javier. "El control de discrecionalidad del planeamiento urbanístico". Civitas 1993.

FERNANDEZ RODRIGUEZ, Tomas Ramón “La legislación española sobre Patrimonio histórico-artístico. Balance de la situación de cara al futuro "Revista de derecho urbanístico (1978) n69.

FERNÁNDEZ RODRÍGUEZ, C., "El paisaje, el medio rural y el patrimonio natural en las recientes iniciativas legislativas estatales. (A propósito de la ratiicación por España de la Convención europea del Paisaje, la Ley 45/2007, de 13 de diciembre, para el desarrollo sostenible del medio rural y la Ley 42/2007, de 13 de diciembre, del Patrimonio Natural y de la Biodiversidad)", en Civitas Revista española de Derecho Administrativo núm. 140/2008

GALVIS GAITÁN Fernando "El municipio colombiano". 4aㅡ Edición. Themis. Bogota 2007.

GARCIA RUBIO, Fernando "Régimen jurídico particular del paisaje urbanoRégimen jurídico particular del paisaje urbano. Entre las determinaciones de adaptación al ambiente, las normas sectoriales y la regulación de la estética en el ámbito de la autonomía local". Dentro de El derecho de la ciudad y el territorio: estudios en homenaje a Manuel Ballbé Prunés / Judith Gifreu i Font (dir.), Martín Bassols Coma (dir.), Angel Menéndez Rexach (dir.), 2016, , págs. 448-473

GIFREU FONT Judith" Las actuaciones sobre el medio urbano como nueva frontera de las políticas públicas al servicio de las de la sostenibilidad territorial y urbanística de la obra colectiva" pags pags 59 a 94 de "Las nuevas perspectivas de la ordenación urbanística y del paisaje :smart cities y rehabilitación. Una perspectiva hispano-italiana GARCIA RUBIO, Fernando (Director) , fundación Democracia y gobierno local , 2017.

WPS RI-SHUR, no6, 2017, vol.2, ISSN: 2387-1768

MONOGRÁFICO SOBRE LAS ESTRATEGIAS DE DESARROLLO URBANO

SOSTENIBLE E INTEGRADO (EDUSI) 


\section{WPSReview International on Sustainable \\ Housing and Urban Renewal (RI-SHUR)}

GONZALEZ-VARAS IBAÑEZ, Santiago "La rehabilitación urbanística "Aranzadi , 1998, pags 33 y ss

LÓPEZ RAMÓN Fernando "Estudios jurídicos sobre ordenación del territorio" Aranzadi 1995.

Perspectivas jurídicas de la rehabilitación urbana Revista española de derecho administrativo,, № 43, 1984, págs. 535-562

MATA OLMO Rafael "Convenio europeo del paisaje del Consejo de Europa. Notas sobre su aplicación en España" Patrimonio cultural y derecho,, № 18, 2014, págs. 175206

MARTIN MATEO, Ramón "Manual de derecho ambiental “ Aranzadi , 2005.

MARTÍN -RETORTILLO BAQUER Sebastián "derecho administrativo económico" La ley 1988. Tomo I

PARADA Ramón lo describe como "jibarización" al respecto vid "Ramón Parada Vázquez "Derecho Urbanístico". Marcial Pons. 2008

PEREZ GONZALEZ, Carlos "Relaciones entre la ordenación urbanística y la protección del paisaje" El Consultor de los Ayuntamientos, № 13, Sección Colaboraciones, Quincena del 15 al 29 Jul. 2008, Ref. 2322/2008, pág. 2322, tomo 2, Editorial LA LEY

PORTO REY, Enrique De la conservación individualizada del patrimonio inmobiliario a su rehabilitación integrada en el planeamiento urbano "Revista de derecho urbanístico №109, 1988, pags 13 y ss.

QUINTANANA LOPEZ, Tomás "Régimen competencial del urbanismo, vivienda y rehabilitación urbana” REALA n²239, 1988 pags 1471-1490.

SÁNCHEZ GOYANES Enrique. "El derecho estatal del suelo tras la refundición de 2008" Pags. 5 a 58 de Especial texto refundido de la ley del suelo. La Ley. 2008

SANTOFIMIO GAMBOA Jaime Orlando "Derecho urbanístico". Bogotá. Universidad Externado de Colombia. 2004. Pags. 36 a 44

SERRANO GUIRAO, E. "La administración local y los problemas de renovación urbana" RAP $n^{\circ} 36,1972$, pags 13 y siguientes.

WPS RI-SHUR, no6, 2017, vol.2, ISSN: 2387-1768

MONOGRÁFICO SOBRE LAS ESTRATEGIAS DE DESARROLLO URBANO

SOSTENIBLE E INTEGRADO (EDUSI) 
WPSReview International on Sustainable

Housing and Urban Renewal (RI-SHUR)

URRUZOLA . Juan Pedro" A propósito de la nueva Ley de Ordenamiento Territorial y sus directrices nacionales"pags 107 a 121 de la revista Pampa № 5, 2009

YOUNES MORENO Diego. Curso de Derecho Administrativo. Editorial Temis S.A. Bogotá 2004. $7^{\text {a }}$ edición

WPS RI-SHUR, no6, 2017, vol.2, ISSN: 2387-1768

MONOGRÁFICO SOBRE LAS ESTRATEGIAS DE DESARROLLO URBANO

SOSTENIBLE E INTEGRADO (EDUSI) 